\title{
Journal of

\section{Synthesis and Biological Properties of Novel Brefeldin A Analogues}

Kai Seehafer, ${ }^{\dagger}$ Frank Rominger, ${ }^{\dagger}$ Günter Helmchen, ${ }^{*}{ }^{\dagger}$ Markus Langhans, ${ }^{\ddagger}$ David G. Robinson, ${ }^{\ddagger}$ Başak Özata, ${ }^{\S}$ Britta Brügger, Jeroen R. P. M. Strating, ${ }^{\perp}$ Frank J. M. van Kuppeveld, ${ }^{\perp}$ and Christian D. Klein ${ }^{\#}$

${ }^{\dagger}$ Institute of Organic Chemistry, University of Heidelberg, Im Neuenheimer Feld 270, 69120 Heidelberg, Germany

${ }^{\ddagger}$ Department of Plant Cell Biology, Centre for Organismal Studies, University of Heidelberg, Im Neuenheimer Feld 230, 69120 Heidelberg, Germany

${ }^{\S}$ Heidelberg University Biochemistry Center, University of Heidelberg, Im Neuenheimer Feld 328, 69120 Heidelberg, Germany

${ }^{\perp}$ Virology Division, Department of Infectious Diseases and Immunology, Faculty of Veterinary Medicine, Utrecht University, Yalelaan 1, 3584 CL Utrecht, The Netherlands

\#Institute of Pharmacy and Molecular Biotechnology (IPMB), University of Heidelberg, Im Neuenheimer Feld 364, 69120 Heidelberg, Germany

\section{Supporting Information}

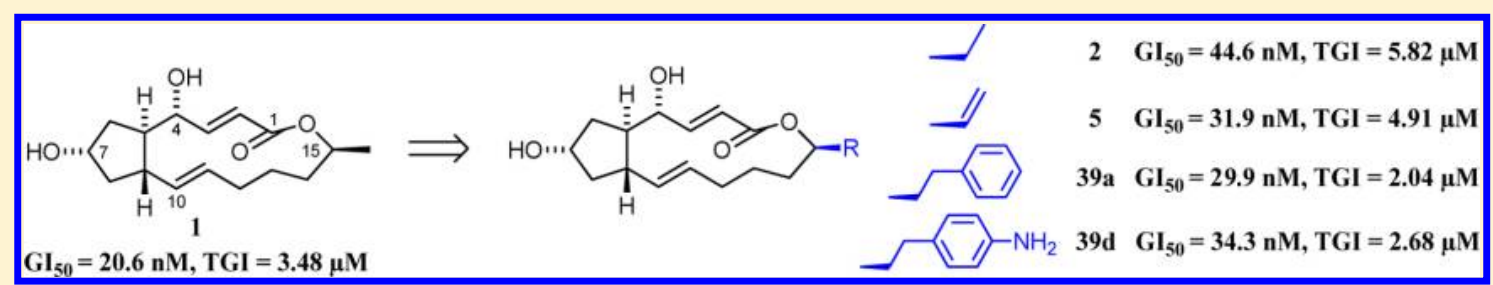

ABSTRACT: New brefeldin A (1) analogues were obtained by introducing a variety of substituents at C15. Most of the analogues exhibited significant biological activity. (15R)-Trifluoromethyl-nor-brefeldin A (3), (15R)-vinyl-nor-brefeldin A (5), their epimers 4 and 6 as well as (15S)-ethyl-nor-brefeldin A (2) were prepared from the key building blocks 12 or 24 by JuliaKocienski olefination with tetrazolyl sulfones and subsequent macrolactonization. The vinyl derivative $\mathbf{5}$ allowed analogues to be synthesized by hydroboration and Suzuki-Miyaura coupling. The following biological properties were assessed: (a) inhibition of cell growth of human cancer cells (NCI), (b) induction of morphological changes of the Golgi apparatus of plant and mammalian cells, and (c) influence on the replication of the enterovirus CVB3. Furthermore, conformational aspects were studied by X-ray crystal structure analysis and molecular mechanics calculations, including docking of the analogues into the brefeldin A binding site of an Arf1/Sec7-complex.

\section{INTRODUCTION}

Brefeldin A (1) (Figure 1) $)^{1}$ is a secondary metabolite of Ascomycetes species. It was first isolated in 1958 by Singleton et al. $^{2}$ from Penicillium decumbens. Brefeldin A is usually

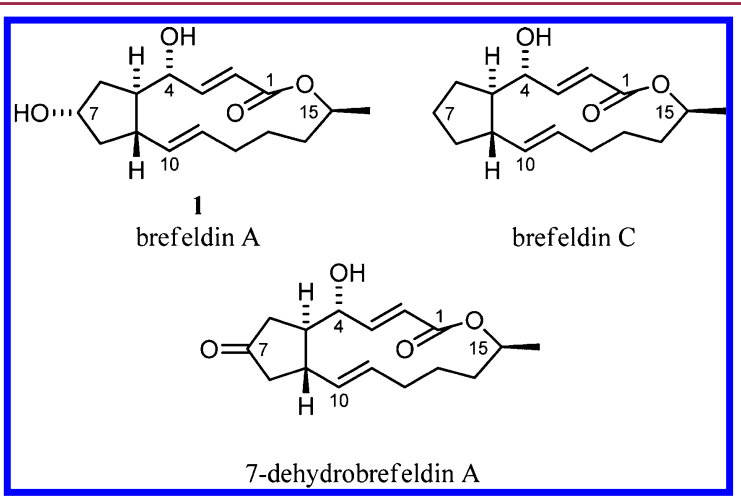

Figure 1. Natural brefeldins. accompanied by its biogenetic precursor brefeldin $\mathrm{C}$ and the oxidation product 7-dehydrobrefeldin $\mathrm{A} .{ }^{3}$ Brefeldin A displays a variety of biological properties, including antifungal, ${ }^{4}$ antiviral, ${ }^{5}$ antinematodal, ${ }^{6}$ and antimitotic ${ }^{7}$ activities. Most important, cytostatic activity through apoptosis against numerous human cancer cell lines was found and prompted $\mathbf{1}$ to be a target for biomedical chemistry. ${ }^{8,9}$

Another aspect of $\mathbf{1}$ has led to its use as a reagent of considerable importance for biomedical research. Treatment of eukaryotic cells with $\mathbf{1}$ induces a reversible morphological disruption, in which the cis Golgi apparatus redistributes into the endoplasmic reticulum (ER), an effect that is caused by the breakdown of vesicle-mediated protein transport between both organelles. ${ }^{10}$ The underlying event involves binding of 1 to a protein complex that is responsible for vesicle budding. This consists of the small G-protein Arf1 (ADP ribosylation factor 1) and a guanidine exchange factor (GEF). ${ }^{11,12}$ The GDP/GTP

Received: April 25, 2013

Published: June 27, 2013 
exchange in Arf1 is catalyzed by Sec7 domain of the GEF. Brefeldin $\mathrm{A}$ acts as a noncompetitive inhibitor by binding reversibly at the interface of both proteins. In 2003, Cherfils et al. ${ }^{13}$ and Goldberg et al. ${ }^{14}$ published X-ray crystal structures of the Arf1/brefeldin A/Sec7-complex and furnished insights into the binding mode of 1 .

Although 1 exhibits strong cytostatic effects paired with low toxicity in mice $\left(\mathrm{LD}_{50}>200 \mathrm{mg} / \mathrm{kg}\right.$, intraperitoneal $),{ }^{4}$ it could not be established as an anticancer drug because of its low bioavailability and poor pharmacokinetics. ${ }^{15}$ Subsequent to our previous synthesis of $\mathbf{1}$ (see below), we decided to synthesize new analogues of $\mathbf{1}$ that could provide better in vivo stability and solubility, perhaps even possessing improved cytostatic activity when compared with 1 . The new analogues were submitted to the National Cancer Institute (NCI), USA, for screening in their Development Therapeutics Program. ${ }^{16}$ Furthermore, the effect on the Golgi apparatus in plant and mammalian cells and replication inhibition of the enterovirus CVB3 were investigated. The analogues were computationally assessed by molecular modeling and docking into the X-ray structure of the Arf1/brefeldin A/Sec7-complex.

A number of analogues of $\mathbf{1}$ have been reported in conjunction with anticancer investigations. The most successful approach is due to Cushman et al. who developed several classes of prodrugs, which in the end yield $\mathbf{1}$ itself as active principle. ${ }^{17 \mathrm{~b}-\mathrm{e}} \mathrm{A}$ second approach was alteration of the structure of 1 itself. Most of the compounds generated in this way showed no or reduced biological activity compared with 1. ${ }^{17}$ There is only one exception, 15-nor-brefeldin A, which was synthesized by our group; ${ }^{17 \mathrm{~h}}$ this compound showed significant activity in tests at the NCI. ${ }^{8 \mathrm{~b}}$ This prompted us to further explore structural variations at $\mathrm{C} 15$. It was decided to begin with the new analogues listed in Figure 2. ${ }^{1}$

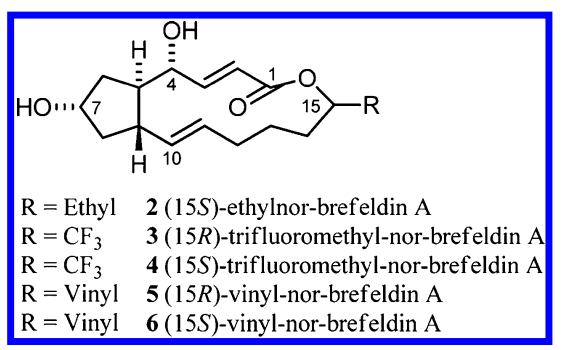

Figure 2. Brefeldin A analogues.

Our syntheses are based on a strategy, see Figure 3, which we have recently reported. ${ }^{17 \mathrm{~g}}$ Key intermediate is the aldehyde $\mathrm{A}$ that is derived from $\mathbf{1}$ by saponification and oxidative cleavage of the lower side chain with $\mathrm{OsO}_{4} /$ periodate. Aldehyde $\mathbf{A}$ can be combined with various tetrazolyl sulfones $\mathbf{B}$ in a convergent and stereoselective manner by Julia-Kocienski olefination. A subsequent macrolactonization usually proceeds with good yield. A particularly versatile early target was (15R)-vinyl-norbrefeldin A (5), from which further derivatives could be efficiently generated in a late stage of their synthesis via addition reactions and Suzuki coupling.

\section{RESULTS AND DISCUSSION}

Synthesis of (15S)-Ethyl-nor-brefeldin A (2). The synthesis of the requisite side chain precursor, the tetrazolyl sulfone 11, is described in Scheme 1. The aldehyde 7, accessible in two steps from commercially available 1,5 -pentanediol, ${ }^{18}$ was

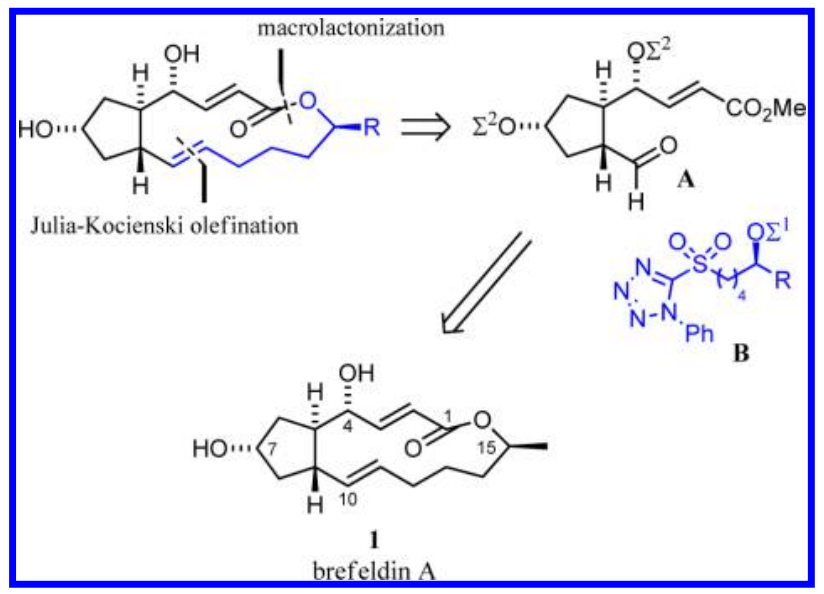

Figure 3. Retrosynthetic analysis ( $\Sigma$ : protecting group).

converted into the enantiomerically enriched alcohol 8 by asymmetric addition ${ }^{19}$ of diethylzinc using (-)-DBNE ${ }^{20}$ as chiral ligand. At a reaction temperature of $0{ }^{\circ} \mathrm{C}, 8$ was obtained in $88 \%$ yield with $87 \%$ ee. TBS-deprotection followed by Mitsunobu reaction with 1-phenyl-1H-tetrazole-5-thiol and protection of the secondary hydroxyl group gave the sulfide 10, which furnished the tetrazolyl sulfone $\mathbf{1 1}$ by $\mathrm{Mo}(\mathrm{VI})$ catalyzed oxidation. $^{21}$

The Julia-Kocienski olefination of tetrazolyl sulfone $\mathbf{1 1}$ and the from 1 derived aldehyde $12^{17 \mathrm{~g}, 22}$ proceeded with essentially complete stereocontrol to give the E-olefin 13 in $73 \%$ yield (Scheme 2). ${ }^{23}$ Selective deprotection gave the hydroxy ester 14, which was saponified to the corresponding hydroxy acid, which was then subjected to macrolactonization under Yamaguchi conditions, yielding 15 in excellent yield of $88 \% .^{24}$ MEMdeprotection with concentrated $\mathrm{HBr}^{17 \mathrm{~h}, 25}$ and purification by recrystallization furnished 2 in $75 \%$ yield.

Synthesis of (15R)- and (15S)-Trifluoromethyl-norbrefeldin A $(3,4)$. Considering that selective substitution of hydrogen by fluorine can affect both pharmacokinetics and pharmacodynamics of a bioactive compound dramatically, ${ }^{26}$ we synthesized an analogue of 1 with the $15-\mathrm{CH}_{3}$ group exchanged for a $\mathrm{CF}_{3}$ group (Scheme 3 ). Using our general strategy, we first prepared the tetrazolyl sulfone 21, starting with the commercially available diol 16. A Mitsunobu reaction followed by a Swern oxidation yielded the aldehyde 18. Reaction of 18 with the Ruppert-Prakash reagent and a catalytic amount of TBAF furnished the racemic alcohol 19. ${ }^{27}$ Subsequent oxidation of the sulfide 19 and TES-protection of the secondary alcohol 20 provided the racemic building block 21 .

The synthesis of the second building block, 24, is described in Scheme 4. We decided to use TBS rather than MEM as protecting group in order to simplify workup and NMR spectra of the synthetic intermediates. First, TBS-protection of the hydroxyl groups of $\mathbf{1}$ to give $\mathbf{2 2}$ was carried out as described by Cushman and co-workers. ${ }^{17 c}$ Subsequent saponification and esterification with diazomethane gave the hydroxy ester 23. This was subjected to selective oxidative cleavage with $\mathrm{OsO}_{4}$ / periodate to furnish the aldehyde 24 in excellent yield.

The building blocks 21 and $\mathbf{2 4}$ were combined by a JuliaKocienski olefination under Barbier-type conditions to provide compound 25 (Scheme 5). Selective TES-deprotection in the presence of the OTBS groups was accomplished with the triethylamine trihydrofluoride complex to yield hydroxy ester 26 in $90 \%$ yield. Saponification and macrolactonization under 
Scheme $1^{a}$

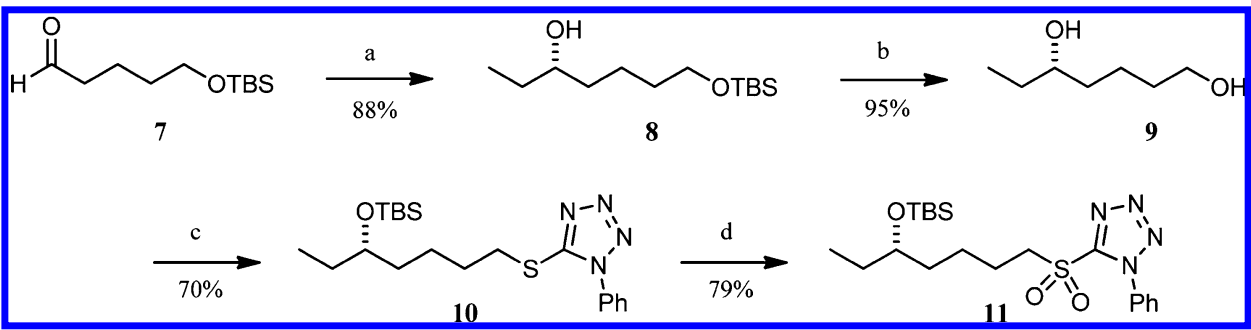

${ }^{a}$ Reagents and conditions: (a) $\mathrm{Et}_{2} \mathrm{Zn},(-)$-DBNE, toluene, $0{ }^{\circ} \mathrm{C}, 24 \mathrm{~h}, 87 \%$ ee; (b) HCl, THF, rt, 20 min; (c) (i) PPh, DEAD, 1-phenyl-1Htetrazole-5-thiol, THF, $0{ }^{\circ} \mathrm{C}$ to rt, $16 \mathrm{~h}$, (ii) TBS-Cl, imidazole, DMAP, $\mathrm{CH}_{2} \mathrm{Cl}_{2}, 0{ }^{\circ} \mathrm{C}$ to rt, $3 \mathrm{~h}$; (d) $\left(\mathrm{NH}_{4}\right)_{6} \mathrm{Mo}_{7} \mathrm{O}_{24} \cdot 4 \mathrm{H}_{2} \mathrm{O}, \mathrm{H}_{2} \mathrm{O}_{2}, \mathrm{EtOH}, \mathrm{rt}, 16 \mathrm{~h}$.

Scheme $2^{a}$

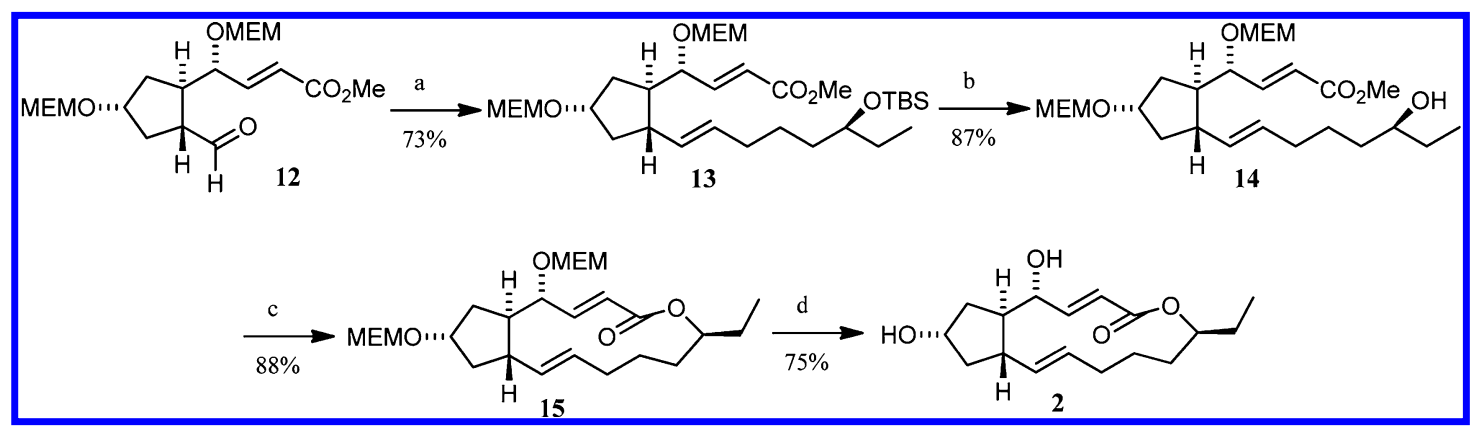

${ }^{a}$ Reagents and conditions: (a) compound 11, KHMDS, 1,2-dimethoxyethane, $-78{ }^{\circ} \mathrm{C}$ to rt, $18 \mathrm{~h}$; (b) HCl, THF, rt, $2 \mathrm{~h}$; (c) (i) LiOH, THF/ $\mathrm{H}_{2} \mathrm{O}$, rt, $2 \mathrm{~h}$, (ii) 2,4,6-trichlorobenzoylchloride, $\mathrm{NEt}_{3}$, THF, rt, 1.5 h, (iii) DMAP, toluene, reflux, $5 \mathrm{~h}$; (d) (i) conc $\mathrm{HBr}$, THF, rt, $1.5 \mathrm{~h},($ ii) recrystallization.

Scheme $3^{a}$

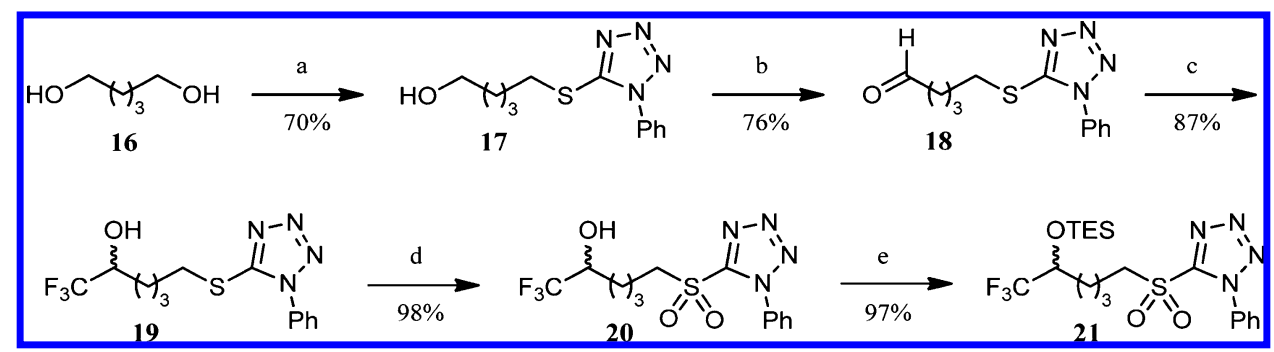

${ }^{a}$ Reagents and conditions: (a) $\mathrm{PPh}_{3}$, DIAD, 1-phenyl- $1 \mathrm{H}$-tetrazole-5-thiol, THF, $0{ }^{\circ} \mathrm{C}$ to rt, $16 \mathrm{~h}$; (b) $(\mathrm{COCl})_{2}, \mathrm{DMSO} \mathrm{NEt}_{3}, \mathrm{CH}_{2} \mathrm{Cl}_{2},-78{ }^{\circ} \mathrm{C}, 45$ min; (c) $\mathrm{CF}_{3}-\mathrm{SiMe}_{3}$, TBAF, THF, $0{ }^{\circ} \mathrm{C}$ to rt, $1 \mathrm{~h}$; (d) $\left(\mathrm{NH}_{4}\right)_{6} \mathrm{Mo}_{7} \mathrm{O}_{24} \cdot 4 \mathrm{H}_{2} \mathrm{O}, \mathrm{H}_{2} \mathrm{O}_{2}, \mathrm{EtOH}, \mathrm{rt}, 16 \mathrm{~h}$; (e) TES-Cl, imidazole, DMAP, $\mathrm{CH}_{2} \mathrm{Cl}_{2}, \mathrm{rt}, 20$ min.

Scheme $4^{a}$

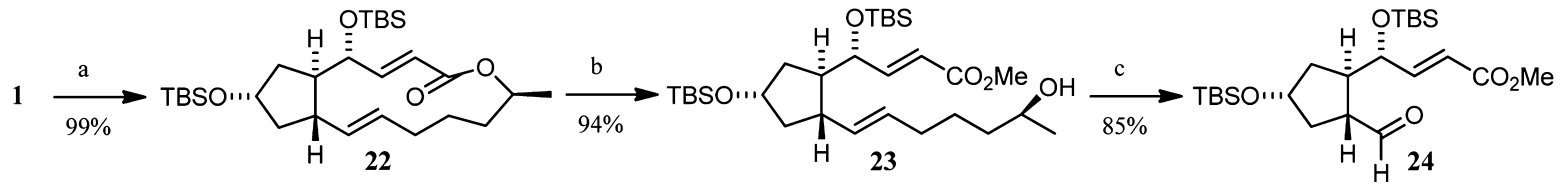

${ }^{a}$ Reagents and conditions: (a) TBS-Cl, imidazole, DMAP, $\mathrm{CH}_{2} \mathrm{Cl}_{2}, 40{ }^{\circ} \mathrm{C}, 20 \mathrm{~h}$; (b) (i) $\mathrm{KOH}, \mathrm{MeOH}, 40{ }^{\circ} \mathrm{C}, 30 \mathrm{~min},(\mathrm{ii}) \mathrm{CH}_{2} \mathrm{~N}_{2}, \mathrm{EtOAc} \mathrm{rt}$; (c) (i) $\mathrm{K}_{2} \mathrm{OsO}_{4} \cdot 2 \mathrm{H}_{2} \mathrm{O}, \mathrm{NMO}$, acetone $/ \mathrm{H}_{2} \mathrm{O}, \mathrm{rt}, 3 \mathrm{~h}$, (ii) $\mathrm{NaIO}_{4}, \mathrm{THF} / \mathrm{H}_{2} \mathrm{O}, \mathrm{rt}, 2 \mathrm{~h}$.

Yamaguchi conditions ${ }^{24}$ furnished the epimers 27 and 28, which could be separated by HPLC. Standard deprotection gave the target compounds 3 and 4 , respectively. The relative configuration of the epimers at $\mathrm{C} 15$ could be assigned by a Xray crystal structure analysis of 3 (Figure 4). Structural assignment of C15-epimers is also generally possible by ${ }^{1} \mathrm{H}$ NMR because for all cyclic compounds there are characteristic differences in chemical shifts (see below).
Synthesis of (15R)- and (15S)-Vinyl-nor-brefeldin A (5, 6). (15S)-Ethyl-nor-brefeldin A (2) displayed promising anticancer activity in tests at NCI (see below). Thus, exploration of the corresponding vinyl derivative, (15R)-vinylnor-brefeldin A (4), was of interest; this compound was also useful as relay for late stage syntheses of further analogues of $\mathbf{1}$. The synthesis of 4 relied on a new procedure for enantioselective synthesis of branched allyl alcohols, an iridium-catalyzed allylic hydroxylation, developed by our 
Scheme $5^{a}$

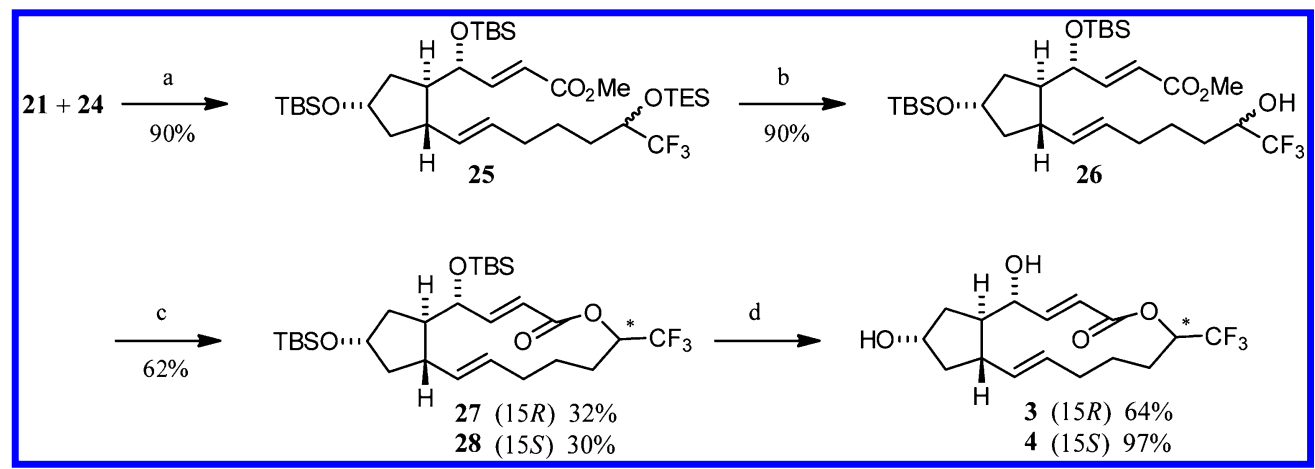

${ }^{a}$ Reagents and conditions: (a) KHMDS, 1,2-dimethoxyethane, $-78{ }^{\circ} \mathrm{C}$ to rt, $16 \mathrm{~h}$; (b) $\mathrm{NEt}_{3} \cdot 3 \mathrm{HF}, \mathrm{CH}_{3} \mathrm{CN}, \mathrm{rt}, 30 \mathrm{~min} ;(\mathrm{c})(\mathrm{i}) \mathrm{NaOH}, \mathrm{THF} / \mathrm{MeOH}$, $60{ }^{\circ} \mathrm{C}, 1 \mathrm{~h}$, (ii) 2,4,6-trichlorobenzoylchloride, $\mathrm{NEt}_{3}$, THF, rt, $2 \mathrm{~h}$, (iii) DMAP, toluene, reflux to rt, $16 \mathrm{~h}$, (iv) separation of 27 and 28 by HPLC; (d) $\mathrm{NEt}_{3} \cdot 3 \mathrm{HF}, \mathrm{CH}_{3} \mathrm{CN}, 60^{\circ} \mathrm{C}, 18 \mathrm{~h}$.

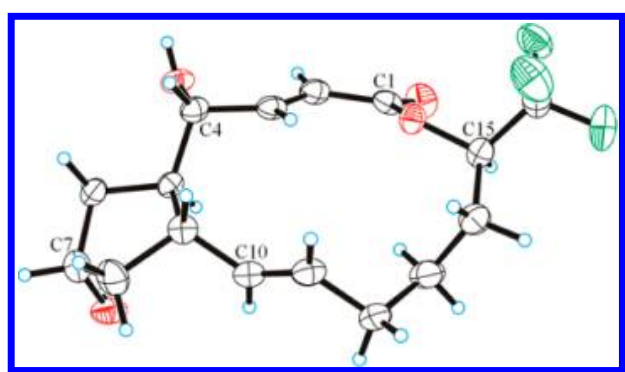

Figure 4. X-ray crystal structure of compound 3.

group. $^{28}$ We decided to apply this procedure in a catalystcontrolled diastereoselective manner to the brefeldin A-derived intermediate 33 (Scheme 7). The side-chain precursor of this compound was prepared as follows (Scheme 6). Aldehyde 18 was subjected to a HWE olefination to give the enoate 29, which was reduced to the allylic alcohol 30. Subsequent carbonate formation and oxidation of the sulfide 31 provided the tetrazolyl sulfone $\mathbf{3 2}$ in excellent overall yield.

Julia-Kocienski olefination of $\mathbf{2 4}$ with $\mathbf{3 2}$ under Barbier-type conditions yielded the methyl carbonate 33 E-selectively in $84 \%$ yield. Next the aforementioned asymmetric iridium-catalyzed allylic hydroxylation was applied, using ( $\pi$-allyl)Ir-complexes C3 (Figure 5) or ent-C3 as catalysts; ${ }^{28}$ alcohols $\mathbf{3 4}$ and $\mathbf{3 5}$ were generated in high yield and diastereoselectivity of 95:5 and 5:95, respectively. Saponification followed by macrolactonization gave the diastereoisomers 36 and 37, which were subjected to the standard deprotection already described to give the diastereomeric target compounds 5 and its epimer 6, respectively.
15-(2-Arylethyl)-nor-brefeldin A Derivatives 39 via Suzuki-Miyaura Coupling. Both (15S)-ethyl-nor-brefeldin A (2) and (15R)-vinyl-nor-brefeldin A (5) showed good cytostatic activity in the NCI assessment (see below), it was therefore of interest to further vary the substituent at C15. First, aryl groups were introduced by Suzuki-Miyaura coupling between di-TBS-protected (15R)-vinyl-nor-brefeldin A (36) and aryl halides. The target compounds and yields are listed in Table 1 . The crucial step of these syntheses was the preparation of a suitable borane by hydroboration of 36 , selectively at the vinyl group rather than double bond $\Delta^{10,11}$. This problem was solved by reaction of 36 with the bulky borane $9-\mathrm{BBN}$ at $70{ }^{\circ} \mathrm{C}$ for $5 \mathrm{~min}$; the subsequent Suzuki-Miyaura coupling gave $38 \mathrm{a}-\mathrm{f}$ in moderate to good overall yield. Deprotection under our standard conditions gave the target compounds $39 a-f$.

nor-Brefeldin A Derivatives with Polar Substituents at C15. The di-TBS-protected (15R)-vinyl-nor-brefeldin A (36) allowed a broad spectrum of compounds considerably more polar than the previous ones to be prepared. The synthesis of the diastereomeric diols $\mathbf{4 2}$ and $\mathbf{4 3}$ was carried out first (Scheme 8) in order to obtain compounds more soluble in water than 1. Asymmetric dihydroxylation (AD) reaction ${ }^{29}$ using an osmium complex of a bulky cinchona alkaloid was expected to favor reaction at the vinyl group. With Sharpless' commercially available $\mathrm{AD}$-mix- $\beta$ (containing (DHQD) ${ }_{2} \mathrm{PHAL}$ as chiral ligand) ${ }^{30}$ diastereoisomers $\mathbf{4 0}$ and $\mathbf{4 1}$ were obtained in overall yield of $44 \%$ in a ratio of ca. 3:1, respectively. The diastereoisomers were separated by HPLC. Deprotection and recrystallization gave pure diols $\mathbf{4 2}$ and $\mathbf{4 3}$.

The diol 40 was used to access (15R)-(hydroxymethyl)-norbrefeldin A (46) (Scheme 9). The aldehyde 44 is prone to

Scheme $6^{a}$

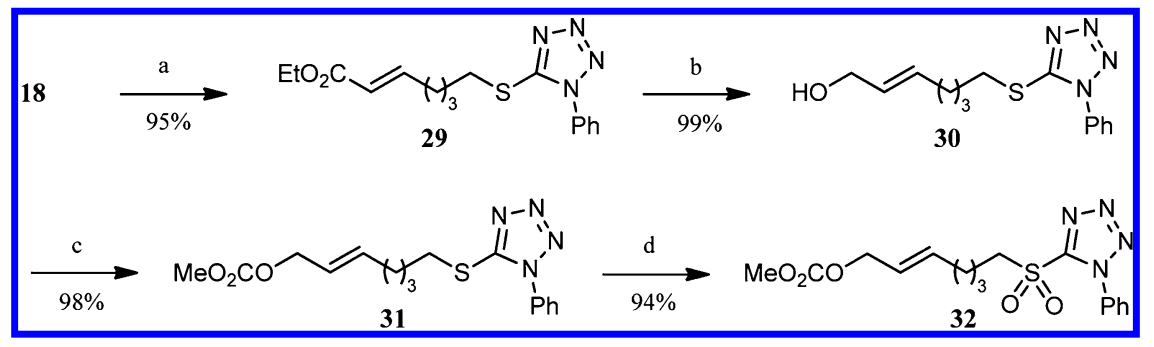

${ }^{a}$ Reagents and conditions: (a) $\mathrm{NaH},(\mathrm{EtO})_{2} \mathrm{P}(\mathrm{O}) \mathrm{CH}_{2} \mathrm{O}_{2} \mathrm{Et}$, THF, $-78{ }^{\circ} \mathrm{C}$ to rt, $14 \mathrm{~h}$; (b) DIBAL-H, THF, $-78{ }^{\circ} \mathrm{C}, 2.5 \mathrm{~h}$; (c) $\mathrm{ClCO} 2 \mathrm{Me}$, pyridine, $\mathrm{CH}_{2} \mathrm{Cl}_{2}, 0{ }^{\circ} \mathrm{C}$ to rt, $1 \mathrm{~h}$; (d) $\left(\mathrm{NH}_{4}\right)_{6} \mathrm{Mo}_{7} \mathrm{O}_{24} \cdot 4 \mathrm{H}_{2} \mathrm{O}, \mathrm{H}_{2} \mathrm{O}_{2}, \mathrm{EtOH}, 0{ }^{\circ} \mathrm{C}$ to rt, $16 \mathrm{~h}$. 
Scheme $7^{a}$

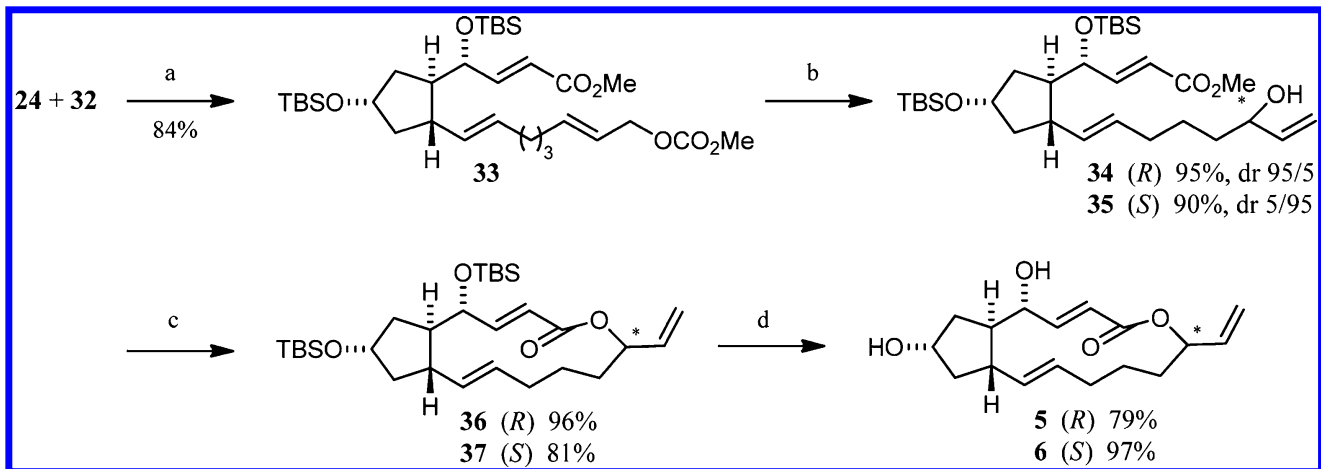

${ }^{a}$ Reagents and conditions: (a) KHMDS, 1,2-dimethoxyethane, $-78{ }^{\circ} \mathrm{C}$ to rt, $18 \mathrm{~h}$; (b) C3 (Figure 5) or ent-C3, $\mathrm{KHCO}_{3}, \mathrm{DMF} / \mathrm{H}_{2} \mathrm{O}, \mathrm{rt}, 3 \mathrm{~h}$; (c) (i) $\mathrm{NaOH}, \mathrm{THF} / \mathrm{MeOH}, 6{ }^{\circ} \mathrm{C}$, (ii) 2,4,6-trichlorobenzoylchloride, $\mathrm{NEt}_{3}$, THF, rt, $2.5 \mathrm{~h}$, (iii) DMAP, toluene, reflux; (d) $\mathrm{NEt} \mathrm{t}_{3} \cdot 3 \mathrm{HF}, \mathrm{CH}_{3} \mathrm{CN} 60{ }^{\circ} \mathrm{C}$, $15 \mathrm{~h}$.

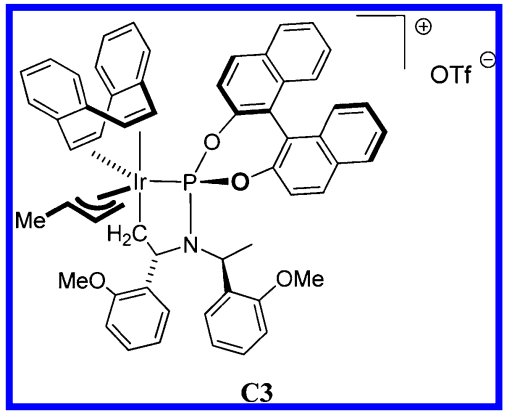

Figure 5. ( $\pi$-Allyl)Ir-complex C3.

epimerization. This could be suppressed by carrying out periodate cleavage with $\mathbf{4 0}$ in a phosphate buffer system. The aldehyde was reduced with $\mathrm{NaBH}_{4}$ to give 45 cleanly after 2 min and in $88 \%$ yield. A short reaction time is necessary in order to prevent intramolecular transesterifiaction (see below). Finally, standard TBS-deprotection and recrystallization gave triol 46 in excellent yield. The homologous alcohol 48 was prepared from the vinyl derivative 36 by hydroboration with 9 BBN and oxidation, followed by standard desilylation (Scheme 10).

With alcohol 47 in hand, it appeared logical to generate ethers such as $\mathbf{5 1}$ and $\mathbf{5 2}$ (Scheme 11). This turned out to be more difficult than anticipated because of facile intramolecular transesterification (see below). After some experimentation, the following procedures gave good results. The methyl ether 49 was obtained by treating a solution of $\mathbf{4 7}$ in methyl iodide with silver(I)-oxide, according to a procedure described by Greene et al. $^{31}$ for a total synthesis of $\mathbf{1}$. The benzyl ether $\mathbf{5 0}$ was similarly prepared in good yield by treating 47 in $\mathrm{BnBr}$ as solvent with a catalytic amounts of TBAI. Standard deprotection gave brefeldin A ether analogues 51 and 52 in high yield.

The intramolecular transesterification mentioned above occurred upon attempted etherification of alcohol 47 with $\mathrm{NaH}$ and $\mathrm{BnBr}$, which gave only a very low yield of the benzyl ether but mainly gave rise to the ring expanded secondary alcohol 53, which was obtained in almost quantitative yield after optimization of the reaction conditions (Scheme 12). Standard deprotection gave the triol 54, which was characterized by X-ray crystal structure analysis (Figure 10C).

Given di-TBS-protected compound 36, it was straightforward to synthesize 15-acetyl-nor-brefeldin A (56) via a Wacker
Table 1. Preparation of Aryl Derivatives 38a-f and 39a-f via Suzuki-Miyaura-Type Coupling and Deprotection ${ }^{a}$

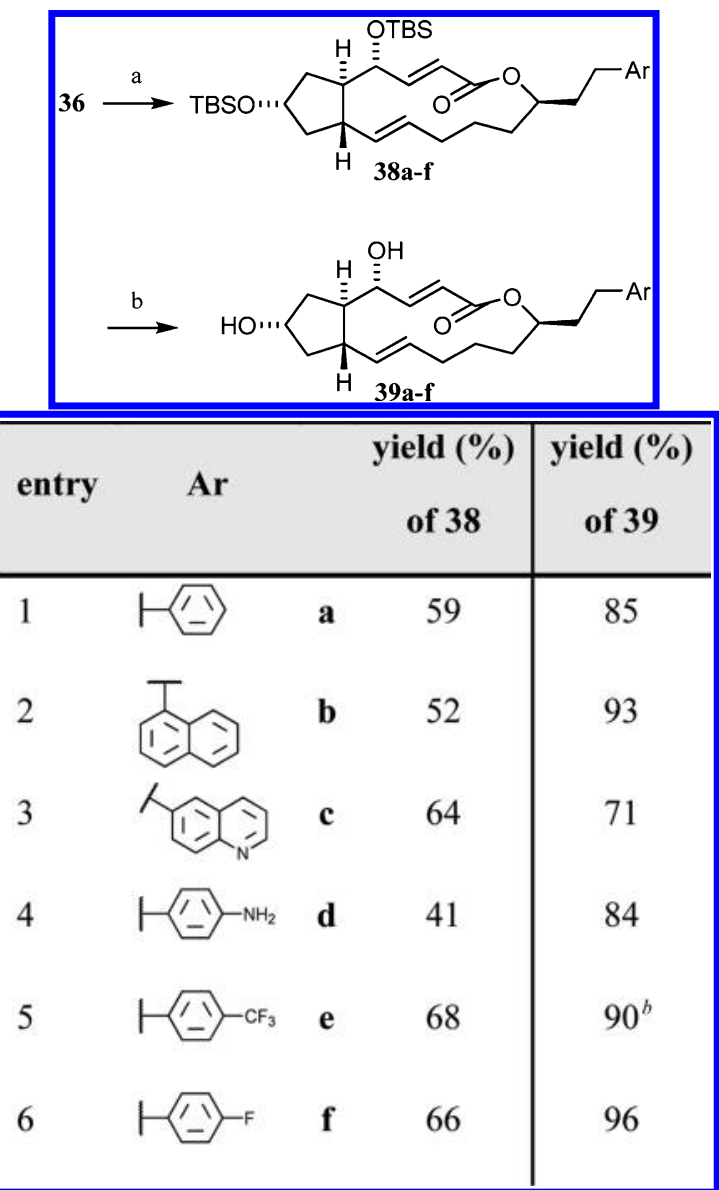

${ }^{a}$ Reagents and conditions: (a) (i) 9-BBN, THF, $70{ }^{\circ} \mathrm{C}, 5 \mathrm{~min}$, (ii) $\mathrm{Ar}$ $\mathrm{X}, \mathrm{Pd}(\mathrm{dppf}) \mathrm{Cl}_{2}, \mathrm{Ph}_{3} \mathrm{As}, \mathrm{Cs}_{2} \mathrm{CO}_{3}, \mathrm{DMF} / \mathrm{H}_{2} \mathrm{O}$, rt or $50{ }^{\circ} \mathrm{C}$; (b) (i) $\mathrm{NEt}_{3} \cdot 3 \mathrm{HF}, \mathrm{CH}_{3} \mathrm{CN}, 60^{\circ} \mathrm{C}, 15 \mathrm{~h}$, (ii) recrystallization. ${ }^{b}$ Reagents and conditions: (i) $\mathrm{HCl}, \mathrm{MeOH}, 40^{\circ} \mathrm{C}, 2 \mathrm{~h}$, (ii) recrystallization.

oxidation $^{32}$ (Scheme 13), anticipating that reaction at the secondary atom of the vinyl group would be favored. The Wacker oxidation was carried out with palladium(II)-chloride, copper(I)-chloride and oxygen to give methyl ketone $\mathbf{5 5}$ in $41 \%$ yield after $23 \mathrm{~h}$ at rt. In addition, the corresponding aldehyde was isolated in $17 \%$ yield. Deprotection of $\mathbf{5 5}$ with triethylamine trihydrofluoride gave the methyl ketone 56 in $87 \%$ yield. 
Scheme $8^{a}$

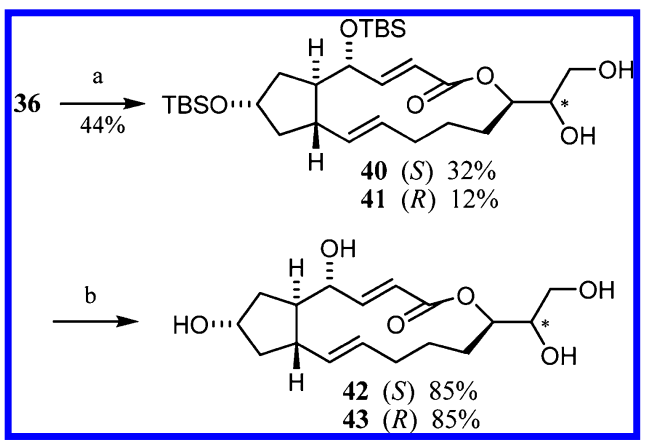

${ }^{a}$ Reagents and conditions: (a) (i) $\mathrm{AD}-\mathrm{Mix}-\beta, \mathrm{MeSO}_{2} \mathrm{NH}_{2}, t-\mathrm{BuOH} /$ $\mathrm{H}_{2} \mathrm{O}$, rt, $16 \mathrm{~h}$, (ii) separation of $\mathbf{4 0}$ and $\mathbf{4 1}$ by HPLC; (b) with 40, (i) $\mathrm{NEt}_{3} \cdot 3 \mathrm{HF}, \mathrm{CH}_{3} \mathrm{CN}, 60{ }^{\circ} \mathrm{C}, 17 \mathrm{~h}$, (ii) recrystallization; with 41, (i) $\mathrm{HCl}$, THF, $40{ }^{\circ} \mathrm{C}, 2 \mathrm{~h}$, (ii) recrystallization.

\section{Scheme $9^{a}$}

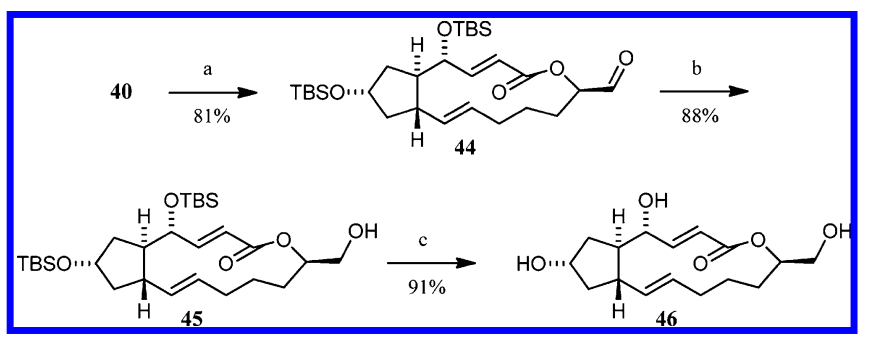

${ }^{a}$ Reagents and conditions: (a) $\mathrm{NaIO}_{4}, \mathrm{THF} / 0.25 \mathrm{M} \mathrm{NaH}_{2} \mathrm{PO}_{4} /$ $\mathrm{Na}_{2} \mathrm{HPO}_{4}$ (pH 7), rt, 1 h; (b) $\mathrm{NaBH}_{4}, \mathrm{THF} / \mathrm{H}_{2} \mathrm{O}, \mathrm{rt}, 2 \mathrm{~min}$; (c) (i) $\mathrm{NEt}_{3} \cdot 3 \mathrm{HF}, \mathrm{CH}_{3} \mathrm{CN}, 60{ }^{\circ} \mathrm{C}, 15 \mathrm{~h}$, (ii) recrystallization.

Scheme $10^{a}$

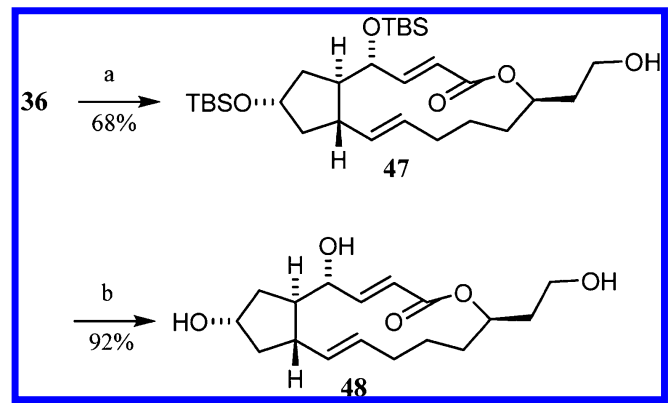

${ }^{a}$ Reagents and conditions: (a) (i) 9-BBN, THF, $70{ }^{\circ} \mathrm{C}, 5 \mathrm{~min}$, (ii) $\mathrm{NaOH}, \mathrm{H}_{2} \mathrm{O}_{2}, 0{ }^{\circ} \mathrm{C}, 20 \mathrm{~min}$; (b) (i) $\mathrm{NEt}_{3} \cdot 3 \mathrm{HF}, \mathrm{CH}_{3} \mathrm{CN}, 60^{\circ} \mathrm{C}, 15 \mathrm{~h}$, (ii) recrystallization.

The analogues derived by Suzuki-Miyaura coupling showed high biological activity. It appeared of interest to add an amide group to the aryl moiety in order to increase polarity and hydrogen bonding capacity (Scheme 14). Accordingly the amine $38 \mathrm{~d}$ was acylated with acetyl chloride to furnish amide 57 after $5 \mathrm{~min}$ in $89 \%$ yield. Standard deprotection gave the amide $\mathbf{5 8}$ in good yield.

Biological Properties of the Brefeldin A Analogues. Anticancer Activity Tested at NCl. Except for 39f, the new analogues of 1 were submitted to the National Cancer Institute (NCI, Maryland, USA) of the U.S. National Institutes of Health for evaluation of their anticancer activity within the Developmental Therapeutics Program (DTP). The substances were first applied to 60 human cancer cell lines including lung, colon, CNS, ovarian, renal, prostate, and breast cancer cell lines
Scheme $11^{a}$

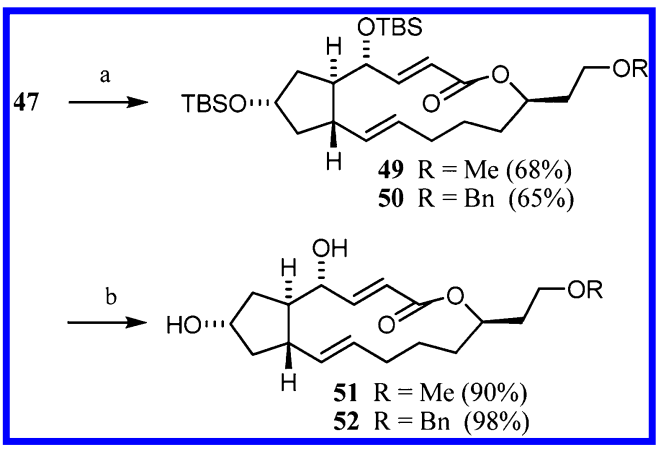

${ }^{a}$ Reagents and conditions: (a) $\mathrm{Ag}_{2} \mathrm{O}, \mathrm{MeI}, \mathrm{rt}, 7.5 \mathrm{~h}$ or $\mathrm{Ag}_{2} \mathrm{O}$, TBAI, $\mathrm{BnBr}, \mathrm{rt}, 7 \mathrm{~h}$; (b) (i) $\mathrm{NEt}_{3} \cdot 3 \mathrm{HF}, \mathrm{CH}_{3} \mathrm{CN}, 60^{\circ} \mathrm{C}, 15 \mathrm{~h}$, (ii) recrystallization.

\section{Scheme $12^{a}$}

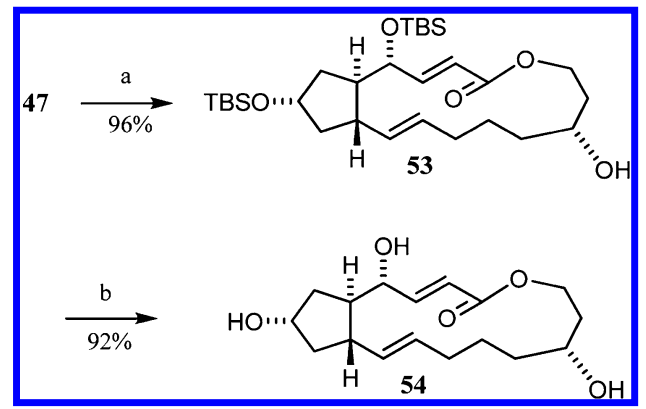

${ }^{a}$ Reagents and conditions: (a) NaH, THF, $0{ }^{\circ} \mathrm{C}, 30 \mathrm{~min}$; (b) (i) $\mathrm{NEt}_{3} \cdot 3 \mathrm{HF}, \mathrm{CH}_{3} \mathrm{CN}, 60^{\circ} \mathrm{C}, 15 \mathrm{~h}$, (ii) recrystallization.

\section{Scheme $13^{a}$}

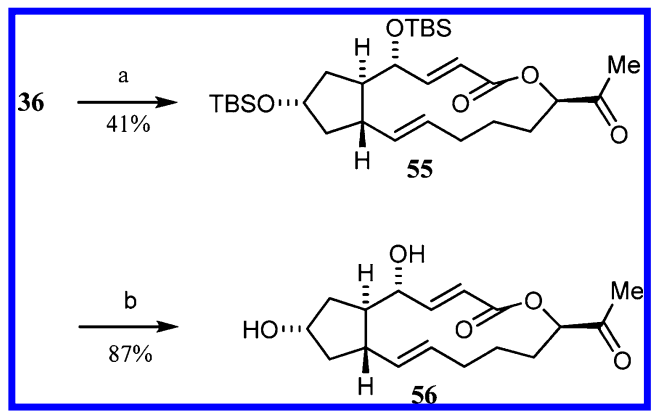

${ }^{a}$ Reagents and conditions: (a) $\mathrm{PdCl}_{2}, \mathrm{CuCl}, \mathrm{O}_{2}, \mathrm{~N}, \mathrm{~N}$-dimethylacetamide $/ \mathrm{H}_{2} \mathrm{O}$, rt, $23 \mathrm{~h}$; (b) (i) $\mathrm{NEt}_{3} \cdot 3 \mathrm{HF}, \mathrm{CH}_{3} \mathrm{CN}, 60{ }^{\circ} \mathrm{C}, 15 \mathrm{~h}$, (ii) recrystallization.

\section{Scheme $14^{a}$.}

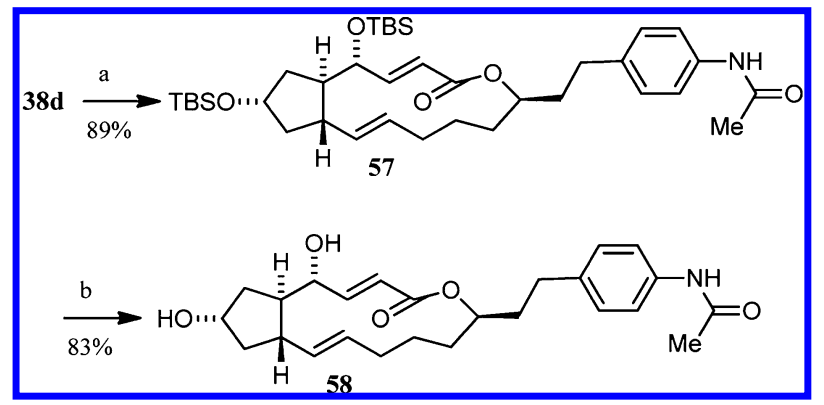

${ }^{a}$ Reagents and conditions: (a) $\mathrm{MeCOCl}, \mathrm{NEt}_{3}$, THF, $0{ }^{\circ} \mathrm{C}, 5 \mathrm{~min}$; (b) (i) $\mathrm{NEt}_{3} \cdot 3 \mathrm{HF}, \mathrm{CH}_{3} \mathrm{CN} / \mathrm{MeOH}, 60^{\circ} \mathrm{C}, 15 \mathrm{~h}$, (ii) recrystallization. 
Table 2. Cytostatic/Cytotoxic Activity of the Active Analogues and 1 against Human Cancer Cell Lines

\begin{tabular}{|c|c|c|c|c|c|}
\hline compound $^{\mathrm{a}}$ & 15-R & $\mathbf{N S C}^{b}$ & $\mathrm{GI}_{50}(\mathrm{nM})^{\mathrm{c}}$ & TGI $(\mu \mathrm{M})^{\mathrm{c}}$ & $\mathbf{L C}_{50}(\boldsymbol{\mu M})^{\mathrm{c}}$ \\
\hline 1 & $\mathrm{CH}_{3}$ & NSC56310 & 20.6 & 3.48 & 52.6 \\
\hline nor-brefeldin $A^{17 h}$ & $\mathrm{H}$ & NSC746708 & $631.0^{\mathrm{d}}$ & $20.9^{\mathrm{d}}$ & $69.2^{\mathrm{d}}$ \\
\hline 2 & $\mathrm{CH}_{2} \mathrm{CH}_{3}$ & NCS755268 & 44.6 & 5.82 & 35.8 \\
\hline 3 & $\mathrm{CF}_{3}$ & NSC763494 & 321.0 & 5.49 & 48.2 \\
\hline 5 & & NSC755269 & 31.9 & 4.91 & 39.0 \\
\hline 6 & /...... & NSC758119 & 630.5 & 17.75 & 66.3 \\
\hline $39 \mathbf{a}$ & & NSC757947 & 29.9 & 2.04 & 40.0 \\
\hline $39 b$ & & NSC761150 & 73.9 & 2.28 & 25.1 \\
\hline $39 \mathrm{c}$ & & NSC761151 & 261.5 & 7.61 & 63.9 \\
\hline 39d & & NSC762147 & 34.3 & 2.68 & 56.3 \\
\hline $39 \mathrm{e}$ & & NSC762150 & 212.0 & 5.97 & 66.2 \\
\hline 46 & & NSC761154 & $2570^{d}$ & $38.00^{\mathrm{d}}$ & $85.1^{d}$ \\
\hline 48 & & NSC757946 & 178.0 & 7.69 & 47.6 \\
\hline 51 & & NSC757948 & 90.2 & 5.78 & 42.3 \\
\hline 52 & & NSC757949 & 80.9 & 5.05 & 35.5 \\
\hline 56 & & NSC761152 & 593.5 & 13.35 & 61.7 \\
\hline 58 & & NSC762149 & 152.0 & 5.70 & 51.6 \\
\hline
\end{tabular}

${ }^{a}$ Compounds that were only assessed by a 1 -dose test are not included. ${ }^{b}$ Internal ID number of the NCI. ${ }^{c}$ Mean values of two different 5 -dose tests. ${ }^{d}$ Values of one 5-dose test.

as well as leukemia and melanoma cells at a high concentration of $10 \mu \mathrm{M}$ (1-dose test). Compounds displaying significant activity were then tested at five different concentrations on the same cells (5-dose test), establishing the parameters $\mathrm{GI}_{50}$ (growth inhibition 50\%; concentration of drug at which cell proliferation is inhibited by 50\%), TGI (total growth inhibition; concentration of drug at which cell proliferation is inhibited by $100 \%$ ), and $\mathrm{LC}_{50}$ (lethal dose $50 \%$; concentration of drug at which $50 \%$ of cell population is killed). ${ }^{16}$ Table 2 provides the results of the five-dose tests as averages of all cell lines. Detailed information, for instance the activities for each cell line, will also soon be published in the database of the $\mathrm{NCI}^{8 \mathrm{~b}}$ As an example, 
the five-dose test results for the highly active analogue $\mathbf{5}$ are given in the Supporting Information.

The analogues $2,5,39 a$, and $39 d$ are highly active, reducing cell growth of colon cancer cells, renal cancer cells and melanoma cells at a comparable concentration as $\mathbf{1}$ does. Moreover, these derivatives display a stronger anticancer effect than 1 on breast cancer cell lines. Slightly lower activities were determined for the naphthyl-derivative $39 \mathrm{~b}, \mathbf{5 1}$, and $\mathbf{5 2}$. (15R)Trifluoromethyl-nor-brefeldin A (3), 39c, 39e, 48, and 58 are less active than 1 , requiring a 10 -fold higher concentration to achieve the same growth inhibition as 1 . Compounds $6,46,56$, and nor-brefeldin $A,{ }^{17 \mathrm{~h}}$ previously synthesized in our group, cause inhibition only at higher concentrations. Almost inactive are the compound 4 , the tetrols 42 and 43 , and the ring expanded analogue $\mathbf{5 4}$ that were not selected for the five-dose screen and are not listed in the table. The same is also true for the (6R)-hydroxybrefeldin A, (7S)-aminobrefeldin C, and the lactam analogue of $\mathbf{1}$ previously synthesized in our laboratory. ${ }^{17 \mathrm{~g}, 33}$

Effects of Brefeldin A Analogues on Plant Cells. As previously carried out, ${ }^{34}$ we have screened the analogues for brefeldin A activity on tobacco leaf protoplasts transiently expressing the fluorescent cis Golgi marker protein Man1-RFP, and on root cells of an Arabidopsis line stably expressing the trans Golgi marker ST-YFP and the trans Golgi network (TGN) marker VHAa1-RFP. As seen in Figure 6, under control conditions the Golgi marker in protoplasts assumes a punctate appearance corresponding to the hundreds of Golgi stacks normally present in a plant cell (Figure 6A). Addition of $\mathbf{1}$ for

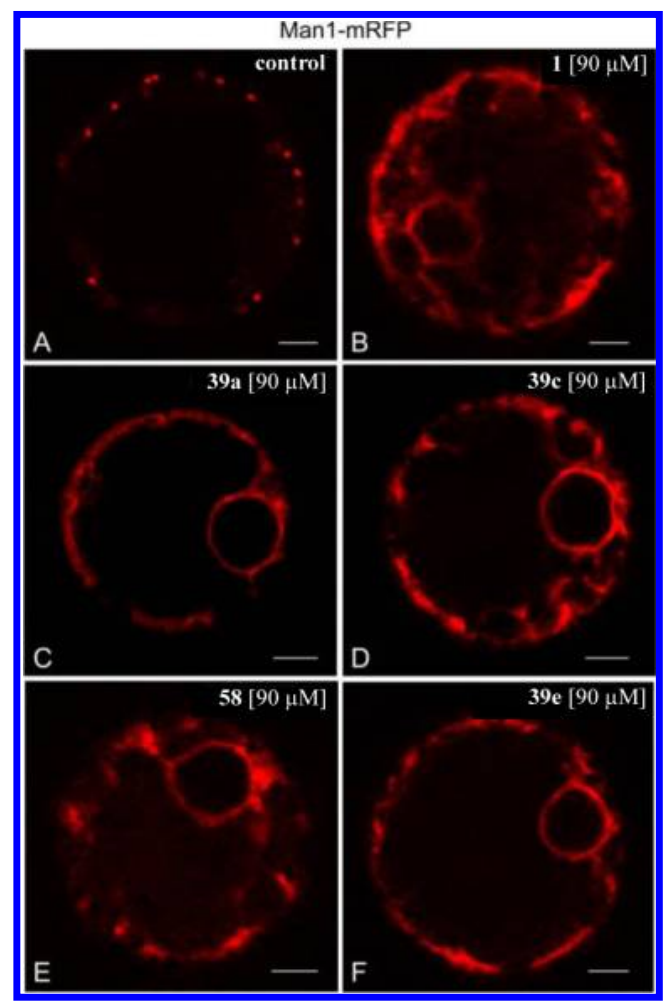

Figure 6. Effects of 1 (B) and analogues 39a, 39c, 58, and 39e (C-F) on tobacco mesophyll protoplasts transiently expressing the cis Golgi marker Man1-RFP. Protoplasts were treated with $90 \mu \mathrm{M}$ of 1 and analogues of $\mathbf{1}$ for $30 \mathrm{~min}$ before observing in the CLSM. The control (A) shows the normal Golgi distribution in plant cells. Magnification bars $(\mathrm{A}-\mathrm{F})=5 \mu \mathrm{m}$.
30 min results in a fusion of the Golgi with the ER with the Golgi marker then becoming distributed throughout the ER network and nuclear envelope (Figure 6B). The same phenotype was observed after application of the analogues 39a, 39c, 58 and 39e (Figure 6C-F). Similarly, the analogues 2 and $\mathbf{5}$ when applied to Arabidopsis roots elicited the same phenotype as $\mathbf{1}$ itself, namely the formation of a "brefeldin Acompartment" with large central core of TGN elements and surrounding Golgi stacks (compare A with B-D in Figure 7).

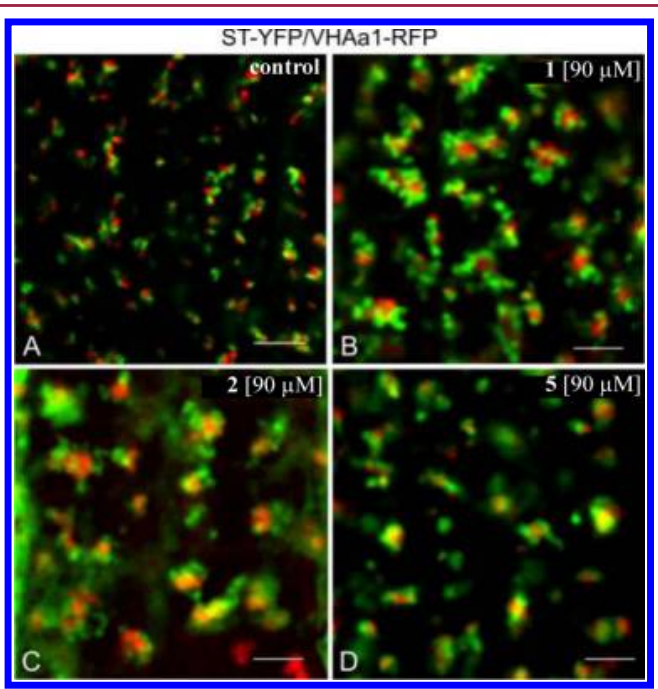

Figure 7. Effects of 1 (B) and brefedlin A analogues 2 (C) and 5 (D) on Arabidopsis root cells stably expressing the Golgi marker ST-YFP and the TGN marker VHAa1-RFP. Roots were treated with $90 \mu \mathrm{M}$ of 1 (B) and analogues of $\mathbf{1}(\mathrm{C}, \mathrm{D})$ for $30 \mathrm{~min}$ before observing in the CLSM. The control (A) shows the normal Golgi and TGN distribution in plant cells. Magnification bars $(\mathrm{A}-\mathrm{D})=5 \mu \mathrm{m}$.

Golgi Disruption in Mammalian Cells. To study Golgi disassembly, HeLa cells were incubated for either 30 or $60 \mathrm{~min}$ in the presence of the various drugs. Cells were fixed and processed as described in the Experimental Section. Visualization of cis Golgi structures was performed using an antiGM130 antibody. Reassembly studies were performed after 60 min incubation in the presence of $\mathbf{1}$ or the indicated analogues, followed by an additional $2 \mathrm{~h}$ incubation in medium in the absence of drug. Immunolabeled cells were analyzed by confocal microscopy (Figure 8). While all drugs tested induced Golgi disassembly, only after removal of substance $39 \mathrm{e}$ was a Golgi reassembly comparable to 1 observed. Substance 39a and $39 \mathrm{~b}$ allowed partial recovery of Golgi structure, whereas the analogue 5 induced an irreversible Golgi disruption.

Replication Inhibition of the Enterovirus CVB3. Brefeldin A is a well-known inhibitor of the replication of enteroviruses. ${ }^{35,36}$ Enteroviruses are a large group ( $>250$ members) of viruses, which includes among others poliovirus (the causative agent of poliomyelitis), the rhinoviruses (common cold), and the coxsackieviruses (the main cause of viral myocarditis, pancreatitis, and meningitis). Enteroviruses have a singlestranded RNA genome of positive-orientation, which is replicated on reorganized intracellular membranes by assemblies of viral proteins and hijacked cellular proteins. ${ }^{37,38}$ These host proteins include GBF1, ${ }^{39-41}$ which is inhibited by $1 .^{42,43}$ To test whether our analogues could also inhibit enterovirus replication, we infected cells with a recombinant coxsackievirus B3 (CVB3) that carried a Renilla luciferase gene ${ }^{41}$ and 


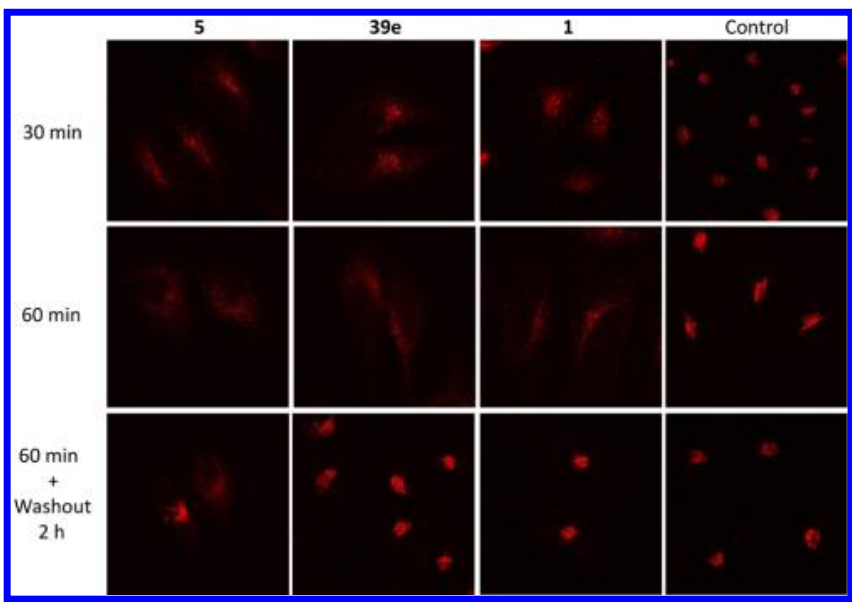

Figure 8. HeLa cells were treated with 1 and the analogues 5 and 39e. Control cells were incubated in medium. After 60 min incubation of cells in the presence of drug, wash-out experiments were performed after removal of the drug by incubating cells for additional $2 \mathrm{~h}$ in medium without drug. Cells were immunolabeled with an anti-GM130 antibody and visualized by confocal microscopy.

subsequently incubated the cells for $7 \mathrm{~h}$ in the presence or absence of compound to allow the replication of the viral genome. Upon viral genome replication, luciferase activity increases exponentially and can be readily assessed as a measure of viral genome replication. At a concentration of $\sim 5 \mu \mathrm{M}, 1$ normally causes a nearly complete inhibition of replication. To assess the potency of the compounds, we tested this concentration and a 10-fold higher and lower concentration.
As shown in Figure 9, we found that at 5 and $50 \mu \mathrm{M}$ all tested compounds inhibited replication of CVB3 to about the same extent as 1 . Only at $0.5 \mu \mathrm{M}$, several analogues inhibited replication to about one log value less than 1 did, except for the analogue 5 , which was about one $\log$ more potent than $\mathbf{1}$, and $39 \mathrm{e}$, which inhibited virus replication clearly less potent than $\mathbf{1}$ at both 5 and $0.5 \mu \mathrm{M}$. This effect on replication was specific and not due to toxicity of the compounds, since at the tested concentrations none of the compounds cause a notable reduction of cell viability (see Supporting Information). Thus, all analogues of $\mathbf{1}$ tested have retained the capability to inhibit the replication of enteroviruses. The vinyl derivative 5 also shows particularly strong inhibition of cancer cell growth, whereas 39e displayed a less strong inhibition of cancer cell growth.

Crystal Structures and NMR Spectra of the Brefeldin A Analogues. X-ray crystal structures of the analogues 2, 3, 5, 6, 39a, 42, 48, and 54 were determined in order to compare the conformations of the new analogues with that of 1 . Superimpositions of the structures of a representative set of analogues with the structure of $\mathbf{1}$ are displayed in Figure 10. For derivative 5, a very close fit is apparent (Figure 10A), with a root-mean-square deviation (rmsd) of only $0.03 \AA$ (based on the core atoms). This is also true for the analogues 2, 3, 39a, 42, and 48, which only differ from 5 in the substituent at C15. However, by changing the configuration at $\mathrm{C} 15$, as in analogue 6, both the conformation of the five- and the 13-membered ring are strongly affected, leading to a much increased rmsd of 0.57 $\AA$ (Figure 10B). The major change is seen for the upper, polar side chain of the 13-membered ring. While these derivatives show the enoate moiety $(\mathrm{O}=\mathrm{C}-\mathrm{C}=\mathrm{C})$ in the natural

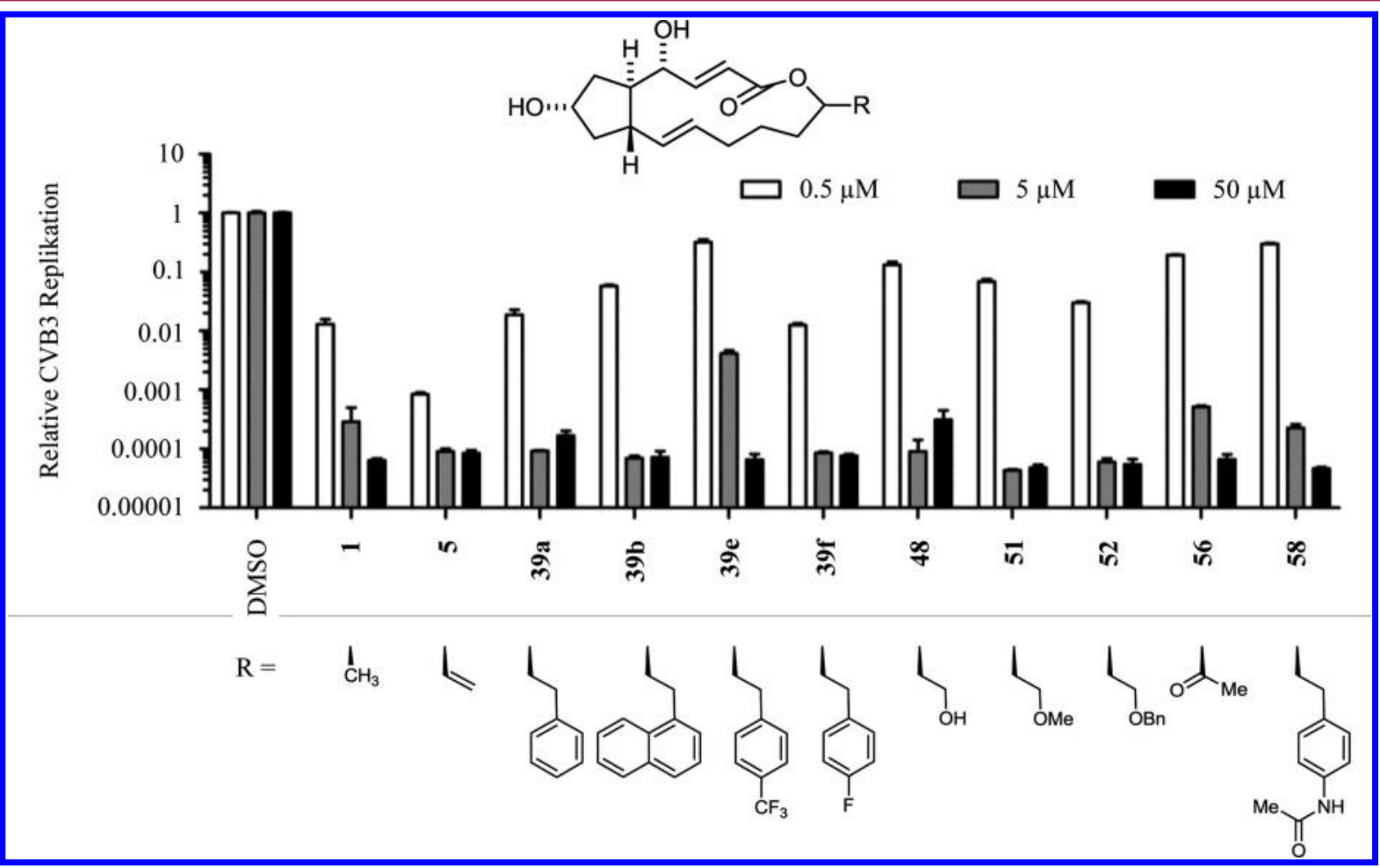

Figure 9. HeLa R19 cells were infected with RLuc-CVB3 virus as described in the Experimental Section procedures and treated with the analogues, 1 or a corresponding dilution of DMSO as a negative control for $7 \mathrm{~h}$. Cells were lysed and the Renilla luciferase activity as a measure of virus replication was measured. Luciferase activity is expressed relative to the control with the same DMSO dilution and shown on a logarithmic scale. Triplicates measurements are shown as means \pm SEM. Like 1, at the concentrations used, the analogues do not considerably affect the viability of the cells within the time frame of the experiment (see Supporting Information). 


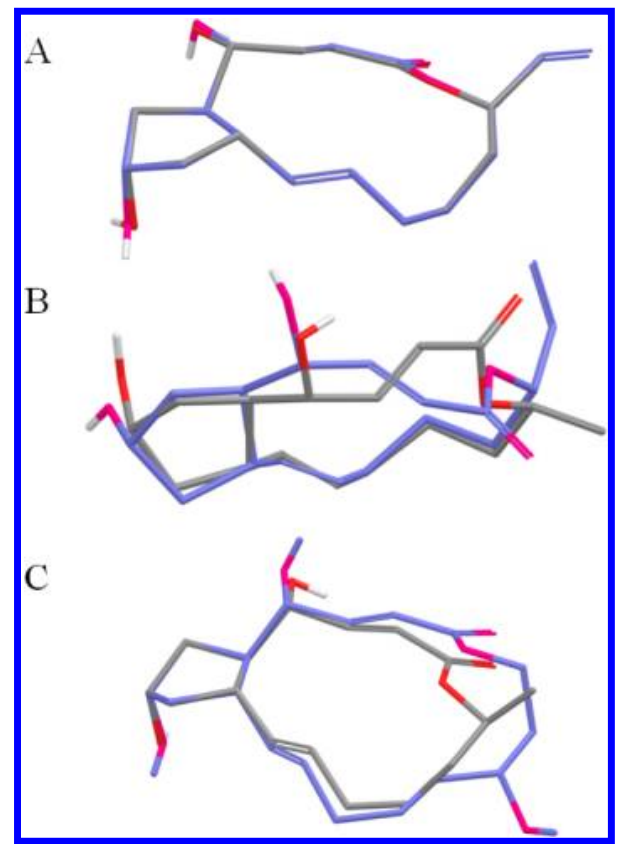

Figure 10. Superpositions of the X-ray crystal structures of different brefeldin A analogues (purple) and 1 (gray). (A) Analogue 5; (B) analogue 6; (C) analogue 54.

occurring s-trans conformation, conformation with respect to the bonds $\mathrm{C} 3-\mathrm{C} 4$ and $\mathrm{C} 4-\mathrm{C} 5$ differ considerably. The ring expanded compound 54 (Figure 10C) is conformationally similar to $\mathbf{1}$ around the five-membered ring, while the conformation of the macrocycle differs considerably.

The differences in the conformational situation of the C15epimers 3 and $\mathbf{4}$ as well as $\mathbf{5}$ and $\mathbf{6}$ are reflected by their ${ }^{1} \mathrm{H}$ NMR spectra (see Supporting Information). Thus, for the analogues $\mathbf{3}$ and $\mathbf{5}$, possessing the same configuration as $\mathbf{1}$, one of the diastereotopic protons at $\mathrm{C}-13$ resonates at $<1 \mathrm{ppm}$ and the olefinic proton at C-3 at $7.5 \mathrm{ppm}$, while for the epimers 4 and 6 the signal of the $13-\mathrm{H}$ is found at $1.4-1.5 \mathrm{ppm}$ and that of the $3-\mathrm{H}$ at $6.8 \mathrm{ppm}$.

Molecular Modeling and Protein-Ligand Docking with the Brefeldin A Analogues. We also investigated the structures of all new analogues by molecular modeling, using the MacroModel ${ }^{44}$ software and a procedure developed by Still et al. that is based on the mmffs force field and a Monte Carlo Multiple Minimum (MCMM) search; they applied this procedure to 7-dehydro-brefeldin A for validation. ${ }^{45}$

As observed in our previous investigation, ${ }^{17 g}$ the calculated minimal energy structures and the X-ray crystal structures of the analogues are superposable for the macrocyclic moiety, while conformers differ for the cyclopentane ring. For this, the conformer with an equatorial 7-OH group is generally preferred in the calculations, while in all crystal structures determined by us the conformer with an axial 7-OH group pertains. However, the energy difference between these conformers is small, calculated as only $0.79 \mathrm{~kJ} / \mathrm{mol}$ for $\mathbf{1}$. Inspection of the crystal structure of $\mathbf{1}$ indicates that hydrogen bonding in the crystal is responsible for the preference of the axial conformer $\left(\mathrm{cf}^{17 \mathrm{~g}}\right.$ ). The conformer with an equatorial 7-OH group was found in the crystal structure of the Arf1/brefeldin A/Sec7-complex.

Docking experiments were carried out with the calculated conformers of lowest energy, using GOLD 5.1 ${ }^{46}$ with ChemPLP as scoring function and the UCSF Chimera package $^{47}$ for visualization. The X-ray crystal structure of the
Arf1/brefeldin A/Sec7-complex from the $\mathrm{PDB}^{48}$ (ID code: $1 \mathrm{RE} 0^{14}$ ) was prepared for docking using the additional programs of the GOLD package. Thus, the ligand 1 was removed from the binding pocket, a new binding pocket was defined (CZ of TYR81, radius $10 \AA$ ), and different rotamers were allowed for four amino acids (ARG19, TRP66, TYR81, VAL270), which are thought to be important with regard to the interactions with the substituents at $\mathrm{C} 15$ of the analogues. Furthermore, water molecules in this region and in the vicinity of the binding site were defined as flexible. Otherwise, the default settings of the GOLD package were used.

The analogues $\mathbf{2}$ and $\mathbf{5}$ scored similar docking scores as $\mathbf{1}$. All the other analogues with the natural configuration at $\mathrm{C} 15$ achieved much higher docking scores. These analogues were docked in a position and orientation (pose) that resembles the pose of $\mathbf{1}$ in the X-ray structure. As example, docking results for (15R)(2-phenylethyl)-nor-brefeldin A (39a) are described in Figure 11 (left); the first three docked poses are superposed.

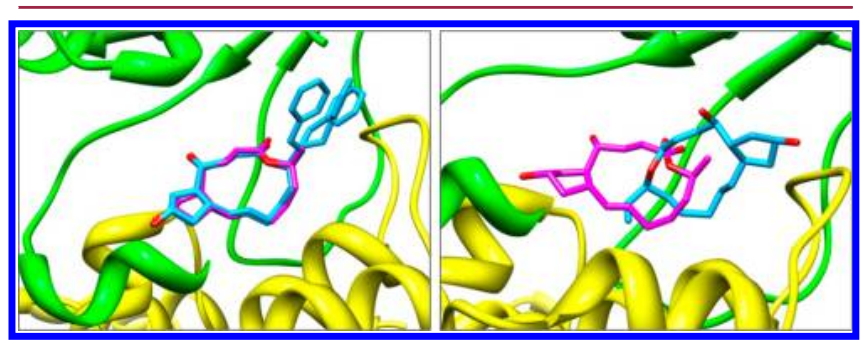

Figure 11. Close-up view of the X-ray crystal complex (PDB ID code: 1RE0) consisting of 1 (purple) in the binding pocket between Arf1 (green ribbon) and Sec7 (yellow ribbon). Left, overlay of the first three docked poses of 39a (turquoise); right, overlay of the docked pose of 6 (turquoise).

Three conformers with different orientation of the aryl group are accepted, implicating that bulky residues at $\mathrm{C} 15$ are well tolerated.

The compounds with the non-natural configuration at $\mathrm{C} 15$, 4,6 , and the ring expanded 54 gave much lower docking scores than 1. These compounds show an anomalous pose, as illustrated by analogue 6 (Figure 11, right).

Relationship of Structure and Cytostatic Activity. Several classes of the analogues of $\mathbf{1}$ can be distinguished (cf. Table 2).

The analogues 2, 5, 39a, and 39b, carrying a nonpolar substituent at C15, are highly active compounds, provide high docking scores, and also show a conformation and docked pose similar to 1 . Even bulky residues at C15, i.e., the 1-naphthyl moiety in $\mathbf{3 9 b}$, are well accepted.

The compounds $\mathbf{4}$ and $\mathbf{6}$, with the non-natural configuration at $\mathrm{C} 15$, and the ring expanded compound $\mathbf{5 4}$ are nearly inactive. The calculated low energy conformers of these compounds differ considerably from that of $\mathbf{1}$, and they possess a low docking score and abnormal docking pose.

The alcohols 42 and 43 with the highly polar 1,2dihydroxyethyl substituent at $\mathrm{C} 15$ display extremely low activity. Very low activity was also obtained for $\mathbf{4 6}$, carrying a hydroxymethyl group at C15, and low activity was found for 48 , and 56, with a 2-hydroxyethyl- and an acetyl group, respectively, at $\mathrm{C} 15$. All these analogues provide high docking scores and conformational similarity to 1 . Accordingly, conformational similarity to $\mathbf{1}$ appears as necessary but not as sufficient condition for cytostatic activity. 
Compounds with a large apolar substituent containing a small polar moiety, 39c with a 7-quinolyl and 39d with a 4aminophenyl group, command interest. While the former is almost inactive, the letter is highly active. However, the $\mathrm{N}$ acetyl derivative 58, derived from $39 \mathrm{~d}$, is inactive.

\section{CONCLUSIONS}

We have synthesized (15R)-trifluoromethyl-nor-brefeldin A (3), (15R)-vinyl-nor-brefeldin A (5), their C15-epimers 4 and 6, as well as (15S)-ethyl-nor-brefeldin A (2). The vinyl derivative $\mathbf{5}$ allowed further analogues to be generated efficiently by hydroboration/Suzuki-Miyaura coupling and other addition reactions. Conformational analyses were carried out by X-ray crystal structure determinations and molecular mechanics calculations. For all brefeldin A analogues, computational docking into the brefeldin A (1) binding site of the Arf1/ Sec7 complex was conducted.

The analogues were tested for their cytostatic effects in human cancer cells. Activity was found for nearly all compounds. High activity was obtained for $\mathbf{2}$ and $\mathbf{5}$ as well as 39a and 39b, bearing a phenyl and a 4-aminophenyl group at C15, respectively. In addition, the ability of inducing morphological changes in the Golgi apparatus in plant and mammalian cells as well as inhibition of the replication of the enterovirus CVB3 in HeLa cells was investigated. In most cases, effects similar to those of $\mathbf{1}$ were found; however, the analogue 5 displayed 10-fold higher activity than 1 against the enterovirus CVB3.

\section{EXPERIMENTAL SECTION}

Details on the synthesis of all compounds are given in the Supporting Information. The purity of all tested compounds was determined by analytical HPLC to be $>95 \%$.

The Effects of Brefeldin A Analogues on Plant Cells. Plants of Arabidopsis thaliana stably transformed with VHAa1-RFP/N-ST$\mathrm{YFP}^{49}$ were grown from surface-sterilized seeds in half-strength Murashige and Skoog (MS) medium ${ }^{50}$ with $1 \%(\mathrm{w} / \mathrm{v})$ sucrose in a controlled climate room at $22{ }^{\circ} \mathrm{C}$ with a $16 \mathrm{~h}$ day length. Transient expression in protoplasts of Nicotiana tabacum cv. Petit Havana was done exactly as described in Langhans et al. in 2011. ${ }^{34}$ Drug Treatment: Control experiments were performed with a standard concentration of $90 \mu \mathrm{M} 1$ (stock solution $5 \mathrm{mg} / \mathrm{mL} 1$ in DMSO) in half MS media for $30 \mathrm{~min}$ or without $\mathbf{1}$ in half MS media and then observed under the microscope. In following experiments plants were treated 30 min with $90 \mu \mathrm{M}$ of different brefeldin A analogues as described before. Analogues were dissolved in DMSO. Confocal microscopy: $80 \mu \mathrm{L}$ protoplast solution of N. tabacum and A. thaliana roots were transferred to slides as previously described in Langhans et al. in $2011 .^{34}$ Cells or plant material were observed under a Zeiss Axiovert LSM510 Meta microscope using a CApochromat 63/1.2 W corr water immersion objective for protoplasts and roots. Special settings were designed for observing single or double expression with different XFPconstructs. Fluorescence was detected by the Metadetector using main beam splitters HFT 488/543. The following fluorophores (excited and emitted by frame switching in the single or multitracking mode) were used: YFP $(488 \mathrm{~nm} / 529-550 \mathrm{~nm})$ and RFP $(543 \mathrm{~nm} / 593-625 \mathrm{~nm})$. Pinholes were adjusted to 1 Airy Unit for each wavelength. Postacquisition image processing was performed using the Zeiss LSM 510 image Browser (4.2.0.121), CorelDrawX4 (14.0.0.567) and ImageJ (1.46o).

Golgi Disruption in Mammalian Cells. As previously described, ${ }^{51}$ HeLa cells were cultivated in Dulbecco's Modified Eagle Medium (DMEM) supplemented with 10\% fetal bovine serum, 100 units $/ \mathrm{mL}$ penicillin, $100 \mu \mathrm{g} / \mathrm{mL}$ streptomycin, and $2 \mathrm{mM}$ L-glutamine. 1 and its analogues were added to cells at a final concentration of 5 $\mu \mathrm{M}$. Cells were incubated at $37^{\circ} \mathrm{C}$ for 30 or $60 \mathrm{~min}$ and then fixed with $4 \%$ paraformaldehyde in phosphate buffered saline (PBS) for 20 $\mathrm{min}$ at rt. Following a $20 \mathrm{~min}$ incubation in $50 \mathrm{mM}$ ammonium chloride at rt, cells were permeabilized for $5 \mathrm{~min}$ at $\mathrm{rt}$ with $0.5 \%$ Triton-X-100 in PBS. Blocking was performed for $15 \mathrm{~min}$ at $\mathrm{rt}$ in 5\% BSA in PBS. Cells were then incubated with an anti-GM130 antibody (BD Transduction Laboratories) for $30 \mathrm{~min}$ at rt. As secondary antibody Alexa Flour 546-coupled-goat-antimouse (Invitrogen, cat. no. A11030) was used. After each step, cells were washes twice for $5 \mathrm{~min}$ in PBS. Cells were mounted in Prolong Gold antifade mounting reagent (Invitrogen) and stored at $4{ }^{\circ} \mathrm{C}$. Immunolabeled cells were protected against light. Immunofluorescence was then analyzed with a Zeiss LSM510 confocal microscope. A Plan-Apochromat $63 \times / 1.4$ Oil DIC objective was used to visualize the cells. The images were processed by FIJI ImageJ 1.46j.

Replication Inhibition of the Enterovirus CVB3. Subconfluent monolayers of HeLa R19 cells were infected for $30 \mathrm{~min}$ at $37^{\circ} \mathrm{C}$ with a Renilla luciferase-expressing Coxsackievirus B3 (RLuc-CVB3) ${ }^{41}$ at a multiplicity of infection (MOI) of $0.1 \mathrm{CCID}_{50}(50 \%$ cell culture infectious dose). After infection, the virus dilution was replaced by medium with $0.5,5$, or $50 \mu \mathrm{M}$ of compound (from a $5 \mathrm{mM}$ stock in DMSO) or the same amount of DMSO only as a negative control. After $7 \mathrm{~h}$, the cells were processed either to measure the amount of luciferase produced as a measure for replication using a Renilla luciferase assay system (Promega, Madison (WI), USA), or for a viability assay using a CellTiter 96 AQueous Non-Radioactive Cell Proliferation Assay (Promega, Madison (WI), USA). Triplicate measurements were normalized to the average of the negative control wells with the same DMSO dilution.

\section{ASSOCIATED CONTENT}

\section{S Supporting Information}

Experimental details and analytical data for all compounds, determination of enantio- or diastereoselectivities for compounds 8, 34, and 35, copies of ${ }^{1} \mathrm{H}$ NMR and ${ }^{13} \mathrm{C}$ NMR spectra of all compounds, NCI 5-dose test results for compound 5, Xray crystal data for compounds $2,3,5,6,39 a, 42,48$, and 54, cell viability during the replication inhibition of CVB3. This material is available free of charge via the Internet at http:// pubs.acs.org.

\section{Accession Codes}

The Cambridge Crystallographic Data Center (CCDC) contains the supplementary crystallographic data for this paper in the Cambridge Structural Database (CSD). CCDC numbers: 925984 for compound 2, 925985 for compound 3, 925986 for compound 5, 925987 for compound 6, 925988 for compound 39a, 925989 for compound 42, 925990 for compound 48, and 925991 for compound $\mathbf{5 4}$.

\section{AUTHOR INFORMATION}

\section{Corresponding Author}

*Phone: +49-6221-548421. Fax: +49-6221-544205. E-mail: g. helmchen@oci.uni-heidelberg.de.

\section{Notes}

The authors declare no competing financial interest.

\section{ACKNOWLEDGMENTS}

This work was supported by the Deutsche Forschungsgemeinschaft (Graduiertenkolleg 850) and the Dr. Rainer WildStiftung and grants from The Netherlands Organisation for Scientific Research (NWO) (an NWO-ALW open program grant and a VICI grant to F.v.K. and a VENI grant to J.S.). The authors thank Patrick Rieger for his kind assistance with cultivation of Eupenicillium brefeldianum. We thank the National Cancer Institute (NCI, U.S. National Institutes of Health, 
Maryland, USA) for performing the anticancer screening within their Developmental Therapeutics Program (DTP).

\section{ABBREVIATIONS USED}

9-BBN, 9-borabicyclo[3.3.1] nonane; (-)-DBNE, (1S,2R)(-)-2-(dibutylamino)-1-phenyl-1-propanol; DEAD, diethyl azodicarboxylate; DIAD, diisopropyl azodicarboxylate; dppf, 1,1'-bis(diphenylphosphino)ferrocene; KHMDS, potassium bis(trimethylsilyl)amide; MEM, methoxyethoxymethyl; NMO, 4-methylmorpholine $\mathrm{N}$-oxide; TBAI, tetrabutylammonium iodide; TES, triisopropylsilyl; TBS, tert-butyldimethylsilyl

\section{REFERENCES}

(1) In text, the common numbering for $\mathbf{1}$ is used (cf. Figures 1 and 2 ). This begins at the carbonyl group and continues anticlockwise around the molecule. In the Supporting Information, for identifying compound names and spectral data, IUPAC numbering is used.

(2) Singleton, V. L.; Bohonos, N.; Ullstrup, A. J. Decumbin. A new compound from a species of Penicillium. Nature 1958, 181, 10721073 .

(3) (a) Sunagawa, M.; Ohta, T.; Nozoe, S. Biosynthesis of Brefeldin A. Introduction of Oxygen at the C-7 Position. J. Antibiot. 1983, 36, 25-29. (b) Yamamoto, Y.; Hori, A.; Hutchinson, C. R. Biosynthesis of Macrolide Antibiotics. 6. Late Steps in Brefeldin A Biosynthesis. J. Am. Chem. Soc. 1985, 107, 2471-2474.

(4) Härri, E.; Loeffler, W.; Sigg, H. P.; Stähelin, H.; Tamm, C. Über die Isolierung neuer Stoffwechselprodukte aus Penicillium brefeldianum DODGE. Helv. Chim. Acta 1963, 46, 1235-1243.

(5) Tamura, G.; Ando, K.; Suzuki, S.; Takatsuki, A.; Arima, K. Antiviral activity of Brefeldin A and Verrucarin A. J. Antibiot. 1968, 21, $160-161$.

(6) Bačíková, D.; Betina, V.; Nemec, P. Antinematodal activity of the antibiotic cyanein. Naturwissenschaften 1964, 51, 445.

(7) Betina, V.; Montagnier, L. Action of cyanein on the synthesis of nucleic acids and proteins in animal cells and bacterial protoplasts. Bull. Soc. Chim. Biol. 1966, 48, 194-198.

(8) (a) Betina, V.; Horáková, K.; Baráth, Z. Anti-HeLa cell effect of cyanein. Naturwissenschaften 1962, 49, 241. (b) DTP Data; Division of Cancer Treatment and Diagnostics, NCI/NIH; http://dtp.nci.nih. gov/docs/dtp_search.html (NSC for 1, 56310; NSC for 15-norbrefeldin A, 746708).

(9) (a) Shao, R. G.; Shimizu, T.; Pommier, Y. Brefeldin A is a Potent Inducer of Apoptosis in Human Cancer Cells Independently of p53. Exp. Cell. Res. 1996, 227, 190-196. (b) Nojiri, H.; Hori, H.; Nojima, S. Induction of Cell Differentiation and Apoptosis into Human Malignant Tumor Cell Lines by Drugs Affecting Ganglioside Biosynthesis. Glycoconjugate J. 1995, 12, 459. (c) Nojiri, H.; Manya, H.; Isono, H.; Yamana, H.; Nojima, S. Induction of terminal differentiation and apoptosis in human colonic carcinoma cells by brefeldin A, a drug affecting ganglioside biosynthesis. FEBS Lett. 1999, $453,140-144$.

(10) Activity of $\mathbf{1}$ in mammalian cells: (a) Fujiwara, T.; Oda, K.; Yokota, S.; Takatsuki, A.; Ikehara, Y. Brefeldin A Causes Disassembly of the Golgi Complex and Accumulation of Secretory Proteins in the Endoplasmic Reticulum. J. Biol. Chem. 1988, 263, 18545-18552. (b) Lippincott-Schwartz, J.; Yuan, L. C.; Bonifacino, J. S.; Klausner, R. D. Rapid Redistribution of Golgi Proteins into the ER in Cells Treated with Brefeldin A: Evidence for Membrane Cycling from Golgi to ER. Cell 1989, 56, 801-813. Activity of 1 in plant cells: (c) Nebenführ, A.; Madison, S. L. Live-Cell Imaging of Dual-Labeled Golgi Stacks in Tobacco BY-2 Cells Reveals Similar Behaviors for Different Cisternae during Movement and Brefeldin A Treatment. Mol. Plant 2011, 4, 896-908. (d) Nebenführ, A.; Ritzenthaler, C.; Robinson, D. G. Brefeldin A: Deciphering an Enigmatic Inhibitor of Secretion. Plant Physiol. 2002, 130, 1102-1108 and literature cited therein.

(11) (a) Donaldson, J. G.; Finazzi, D.; Klausner, R. D. Brefeldin A inhibits Golgi membrane-catalysed exchange of guanine nucleotide onto ARF protein. Nature 1992, 360, 350-352. (b) Helms, J. B.; Rothman, J. E. Inhibition by brefeldin A of a Golgi membrane enzyme that catalyses exchange of guanine nucleotide bound to ARF. Nature 1992, 360, 350-352.

(12) For the mechanism of vesicle budding and the function of Gproteins in this context see: (a) Rothman, J. E.; Wieland, F. T. Protein Sorting by Transport Vesicles. Science 1996, 272, 227-234. (b) Brügger, B.; Wieland, F. T. Mechanismen der COPIVesikelbiogenese. Biospektrum 2004, 1, 30-33. (c) Bonifacino, J. S.; Lippincott-Schwartz, J. Coat proteins: shaping membrane transport. Nature Rev. Mol. Cell Biol. 2003, 4, 409-414.

(13) Renault, L.; Guibert, B.; Cherfils, J. Structural snapshots of the mechanism and inhibition of a guanine nucleotide exchange factor. Nature 2003, 426, 525-530.

(14) Mossessova, E.; Corpina, R. A.; Goldberg, J. Crystal Structure of ARF1-Sec7 Complexed with Brefeldin A and Its Implications for the Guanine Nucleotide Exchange Mechanism. Mol. Cell 2003, 12, 14031411.

(15) Phillips, L. R.; Supko, J. G.; Malspeis, L. Analysis of Brefeldin A in Plasma by Gas Chromatography with Electron Capture Detection. Anal. Biochem. 1993, 211, 16-22.

(16) For more information see: Developmental Therapeutics Program; Division of Cancer Treatment and Diagnostics, NCI/NIH; http://dtp. nci.nih.gov.

(17) For brefeldin analogues derived from 1 see: (a) Zhu, J.-W.; Hori, H.; Nojiri, H.; Tsukuda, T.; Taira, Z. Synthesis And Activity Of Brefeldin A Analogs As Inducers Of Cancer Cell Differentiation And Apoptosis. Bioorg. Med. Chem. Lett. 1997, 7, 139-144. (b) Argade, A. B.; Devraj, R.; Vroman, J. A.; Haugwitz, R. D.; Hollingshead, M.; Cushman, M. Design and Synthesis of Brefeldin A Sulfide Derivatives as Prodrug Candidates with Enhanced Aqueous Solubilities. J. Med. Chem. 1998, 41, 3337-3346. (c) Argade, A. B.; Haugwitz, R. D.; Devraj, R.; Kozlowski, J.; Fanwick, P. E.; Cushman, M. Highly Efficient Diastereoselective Michael Addition of Various Thiols to (+)-Brefeldin A. J. Org. Chem. 1998, 63, 273-278. (d) Fox, B. M.; Vroman, J. A.; Fanwick, P. E.; Cushman, M. Preparation and Evaluation of Sulfide Derivatives of the Antibiotic Brefeldin A as Potential Prodrug Candidates with Enhanced Aqueous Solubilities. J. Med. Chem. 2001, 44, 3915-3924. (e) Anadu, N. O.; Davisson, V. J.; Cushman, M. Synthesis and Anticancer Activity of Brefeldin A Ester Derivatives. J. Med. Chem. 2006, 49, 3897-3905. (f) Ref 17g. For brefeldin analogues derived by total synthesis see: (g) Förster, S.; Persch, E.; Tverskoy, O.; Rominger, F.; Helmchen, G.; Klein, C.; Gönen, B.; Brügger, B. Syntheses and Biological Properties of Brefeldin Analogues. Eur. J. Org. Chem. 2011, 878-891. (h) Hübscher, T.; Helmchen, G. Enantioselective Formal Synthesis of Brefeldin A and Analogues via Anionic Cyclization of an Alkenyl Epoxide. Synlett 2006, 1323-1326. (i) Förster, S.; Helmchen, G. Stereoselective Synthesis of a Lactam Analogue of Brefeldin C. Synlett 2008, 831-836. (j) Paek, S.M.; Seo, S.-Y.; Min, K.-H.; Shin, D. M.; Chung, Y. K.; Suh, Y.-G. Synthesis of Lactam Analogue of 4-epi-Brefeldin A. Heterocycles 2007, 71, 1059-1066. (k) Gao, J.; Huang, Y.-X.; Wu, Y. Enantioselective total synthesis of 13-O-brefeldin A. Tetrahedron 2008, 64, 1110511109. (1) Archambaud, S.; Aphecetche-Julienne, K.; Guingant, A. A New Total Synthesis of (+)-Brefeldin C. Synlett 2005, 139-143. (m) Archambaud, S.; Legrand, F.; Aphecetche-Julienne, K.; Collet, S.; Guingant, A.; Evain, M. Total Synthesis of (+)-Brefeldin C, (+)-norMe Brefeldin A and (+)-4-epi-nor-Me Brefeldin A. Eur. J. Org. Chem. 2010, 1364-1380. (n) Inai, M.; Nishii, T.; Mukoujima, S.; Esumi, T.; Kaku, H.; Tominaga, K.; Abe, H.; Horikawa, M.; Tsunoda, T. Total Synthesis of (+)-Brefeldin C Utilizing Aza-Claisen Rearrangement. Synlett 2011, 1459-1461.

(18) Kozikowski, A. P.; Shum, P. W.; Basu, A.; Lazo, J. S. Synthesis of structural analogues of lyngbyatoxin $A$ and their evaluation as activators of protein kinase C. J. Med. Chem. 1991, 34, 2420-2430.

(19) Reviews: (a) Soai, K.; Niwa, S. Enantioselective Addition of Organozinc Reagents to Aldehydes. Chem. Rev. 1992, 92, 833-856. (b) Pu, L.; Yu, H.-B. Catalytic Asymmetric Organozinc Additions to Carbonyl Compounds. Chem. Rev. 2001, 101, 757-824. 
(20) Soai, K.; Yokoyama, S.; Ebihara, K.; Hayasaka, T. A New Chiral Catalyst for the Highly Enantioselective Addition of Dialkylzinc Reagents to Aliphatic Aldehydes. J. Chem. Soc., Chem. Commun. 1987, $1690-1691$.

(21) Blakemore, P. R.; Kocienski, P. J.; Marczak, S.; Wicha, J. The Modified Julia Olefination in Vitamin $\mathrm{D}_{2}$ Synthesis. Synthesis 1999, $1209-1215$.

(22) For syntheses of $\mathbf{2 4}$ not starting from $\mathbf{1}$ see: Haynes, R. K.; Lam, W. W.-L.; Yeung, L.-L.; Williams, I. D.; Ridley, A. C.; Starling, S. M.; Vonwiller, S. C.; Hambley, T. W.; Lelandais, P. Highly diastereoselective conjugate addition of lithiated $\gamma$-crotonolactone (but-2-en4-olide) to cyclic enones to give syn-adducts: application to a brefeldin synthesis. J. Org. Chem. 1997, 62, 4552-4553.

(23) Trost, B. M.; Crawley, M. L. A "chiral aldehyde" equivalent as a building block towards biologically active targets. Chem.-Eur. J. 2004, 10, 2237-2252. This article also contains an extensive bibliography on previous total syntheses of $\mathbf{1}$.

(24) Inanaga, J.; Hirata, K.; Saeki, H.; Katsuki, T.; Yamaguchi, M. A rapid esterification by means of mixed anhydride and its application to large-ring lactonization. Bull. Chem. Soc. Jpn. 1979, 52, 1989-1993.

(25) Williams, D. R.; Jass, P. A.; Tse, H.-L. A.; Gaston, R. D. Total Synthesis of (+)-breynolide. J. Am. Chem. Soc. 1990, 112, 4552.

(26) Reviews: (a) Müller, K.; Faeh, C.; Diederich, F. Fluorine in pharamceuticals: looking beyond intuition. Science 2007, 317, 18811886. (b) Purser, S.; Moore, P. R.; Swallow, S.; Gouverneur, V. Fluorine in medicinal chemistry. Chem. Soc. Rev. 2008, 37, 320-330. (c) O'Hagan, D. Understanding organofluorine chemistry. An introduction to the C-F bond. Chem. Soc. Rev. 2008, 37, 308-319.

(27) (a) Ruppert, I.; Schlich, K.; Volbach, W. Die ersten $\mathrm{CF}_{3}$ substituierten Organyl(chlor)silane. Tetrahedron Lett. 1984, 25, 21952198. (b) Prakash, G. K. S.; Krishnamurti, R.; Olah, G. A. Fluorideinduced trifluoromethylation of carbonyl compounds with trifluormethyltrimethylsilane (TMS- $\mathrm{CF}_{3}$ ). A trifluormethide equivalent. J. Am. Chem. Soc. 1989, 111, 393-395.

(28) (a) Gärtner, M.; Mader, S.; Seehafer, K.; Helmchen, G. Enantioand regioselective iridium-catalyzed allylic hydroxylation. J. Am. Chem. Soc. 2011, 133, 2072-2075. (b) Spiess, S.; Welter, C.; Franck, G.; Taquet, J.-P.; Helmchen, G. Iridium-catalyzed asymmetric allylic substitutions-very high regioselectivity and air stability with a catalyst derived from dibenzo[a,e]cyclooctatetraene and a phosphoramidite. Angew. Chem., Int. Ed. 2008, 47, 7652-7655. (c) Raskatov, J. A.; Spiess, S.; Gnamm, C.; Brödner, K.; Rominger, F.; Helmchen, G. Ircatalysed asymmetric allylic substitutions with cyclometalated (phosphoramidite)Ir complexes-resting states, catalytically active $(\pi$-allyl)Ir complexes and computational exploration. Chem.-Eur. J. 2010, 6601-6615.

(29) Reviews: (a) Kolb, H. C.; VanNieuwenhze, M. S.; Sharpless, K. B. Catalytic asymmetric dihydroxylation. Chem. Rev. 1994, 94, 24832547. (b) Lohray, B. B. Recent advances in the asymmetric dihydroxylation of alkenes. Tetrahedron: Asymmetry 1992, 3, 13171349.

(30) Sharpless, K. B.; Amberg, W.; Bennani, Y. L.; Crispino, G. A.; Hartung, J.; Jeong, K.-S.; Kwong, H.-L.; Morikawa, K.; Wang, Z.-M.; Xu, D.; Zhang, X.-L. The osmium-catalyzed asymmetric dihydroxylation: a new ligand class and a process improvement. J. Org. Chem. 1992, 57, 2768-2771.

(31) Greene, A. E.; Le Drian, C.; Crabbé, P. An efficient total synthesis of ( \pm )-Brefeldin-A. J. Am. Chem. Soc. 1980, 102, 7583-7584.

(32) Review: Tsuji, J. Synthetic applications of the palladiumcatalyzed oxidation of olefins to ketones. Synthesis 1984, 5, 369-384.

(33) Internal ID numbers of the NCI (NSC) for compounds not listed in Table 2: 4 (NSC763496), 42 (NSC761153), 43 (NSC761155), 54 (NSC757950), (6R)-hydroxybrefeldin A (NSC751150), (7S)-aminobrefeldin C (NSC671437), lactam analogue of 1 (NSC652682).

(34) Langhans, M.; Förster, S.; Helmchen, G.; Robinson, D. G. Differential effects of the brefeldin A analogue (6R)-hydroxy-brefeldin A in tobacco and Arabidopsis. J. Exp. Bot. 2011, 62, 2949-2957.
(35) Irurzun, A.; Perez, L.; Carrasco, L. Involvement of membrane traffic in the replication of poliovirus genomes: effects of brefeldin A. Virology 1992, 191, 166-175.

(36) Maynell, L. A.; Kirkegaard, K.; Klymkowsky, M. W. Inhibition of Poliovirus RNA Synthesis by Brefeldin A. J. Virol. 1992, 66, 19851994.

(37) Hsu, N.-Y.; Ilnytska, O.; Belov, G.; Santiana, M.; Chen, Y.-H.; Takvorian, P. M.; Pau, C.; van der Schaar, H.; Kaushik-Basu, N.; Balla, T.; Cameron, C. E.; Ehrenfeld, E.; van Kuppeveld, F. J. M.; AltanBonnet, N. Viral Reorganization of the Secretory Pathway Generates Distinct Organelles for RNA Replication. Cell 2010, 141, 799-811.

(38) Nagy, P. D.; Pogany, J. The dependence of viral RNA replication on co-opted host factors. Nature Rev. Microbiol. 2011, 10, 137-149.

(39) Wessels, E.; Duijsings, D.; Niu, T.-K.; Neumann, S.; Oorschot, V. M.; de Lange, F.; Lanke, K. H. W.; Klumperman, J.; Henke, A.; Jackson, C. L.; Melchers, W. J. G.; van Kuppeveld, F. J. M. A Viral Protein that Blocks Arf1-Mediated COP-I Assembly by Inhibiting the Guanine Nucleotide Exchange Factor GBF1. Dev. Cell 2006, 11, 191201

(40) Belov, G. A.; Altan-Bonnet, N.; Kovtunovych, G.; Jackson, C. L.; Lippincott-Schwartz, J.; Ehrenfeld, E. Hijacking Components of the Cellular Secretory Pathway for Replication of Poliovirus RNA. J. Virol. 2007, 81, 558-567.

(41) Lanke, K. H. W.; van der Schaar, H. M.; Belov, G. A.; Feng, Q.; Duijsings, D.; Jackson, C. L.; Ehrenfeld, E.; van Kuppeveld, F. J. M. GBF1, a Guanine Nucleotide Exchange Factor for Arf, Is Crucial for Coxsackievirus B3 RNA Replication. J. Virol. 2009, 83, 11940-11949.

(42) Mansour, S. J.; Skaug, J.; Zhao, X.-H.; Giordano, J.; Scherer, S. W.; Melançon, P. p200 ARF-GEP1: a Golgi-localized guanine nucleotide exchange protein whose Sec7 domain is targeted by the drug brefeldin A. Proc. Natl. Acad. Sci. U. S. A. 1999, 96, 7968-7973.

(43) Peyroche, A.; Antonny, B.; Robineau, S.; Acker, J.; Cherfils, J.; Jackson, C. L. Brefeldin A Acts to Stabilize an Abortive ARF-GDPSec7 Domain Protein Complex: Involvement of Specific Residues of the Sec7 Domain. Mol. Cell 1999, 3, 275-285.

(44) MacroModel is a product of Schrödinger, LLC; for detailed information see: MacroModel; Schrödinger, LLC: New York, 2013; http://www.schrodinger.com/products/14/11.

(45) (a) Chang, G.; Guida, W. C.; Still, W. C. An Internal Coordinate Monte Carlo Method for Searching Conformational Space. J. Am. Chem. Soc. 1989, 111, 4379-4386. (b) Method details: mmffs, energy minimization by a conjugate gradient method (PRCG), Monte Carlo Multiple Minimum (MCMM) conformational search using the implemented automatic setup, $\mathrm{H}_{2} \mathrm{O}$ was used as solvent model.

(46) (a) Jones, G.; Willett, P.; Glen, R. C.; Leach, A. R.; Taylor, R. Development and Validation of a Genetic Algorithm for Flexible Docking. J. Mol. Biol. 1997, 267, 727-748. (b) For more information see: GOLD 5.1; Cambridge Crystallographic Data Centre: Cambridge, UK; http://www.ccdc.cam.ac.uk/products/life_sciences/gold.

(47) (a) Pettersen, E. F.; Goddard, T. D.; Huang, C. C.; Couch, G. S.; Greenblatt, D. M.; Meng, E. C.; Ferrin, T. E. UCSF Chimera-A Visualization System for Exploratory Research and Analysis. J. Comput. Chem. 2004, 25, 1605-1612. (b) For more information see: UCSF Chimera, An Extensible Molecular Modeling System; University of California, San Francisco: San Francisco, CA; http://www.cgl.ucsf. edu/chimera.

(48) Biological Macromolecular Resource; RCSB Protein Data Bank; http://www.rcsb.org/pdb/home/home.do.

(49) Dettmer, J.; Hong-Hermesdorf, A.; Stierhof, Y.-D.; Schumacher, K. Vacuolar $\mathrm{H}^{+}$-ATPase Activity Is Required for Endocytic and Secretory Trafficking in Arabidopsis. Plant Cell 2006, 18, 715-730.

(50) Murashige, T.; Skoog, F. A. A Revised Medium for Rapid Growth and Bio Assays with Tobacco Tissue Cultures. Physiol. Plant. 1962, 15, 473-497.

(51) Rutz, C.; Satoh, A.; Ronchi, P.; Brügger, B.; Warren, G.; Wieland, F. T. Following the Fate In Vivo of COPI Vesicles Generated In Vitro. Traffic 2009, 10, 994-1005. 